\title{
A Cylindrical Cell for Operando Neutron Diffraction of Li-lon Battery Electrode Materials
}

\author{
Laura Vitoux ${ }^{1,2+}$, Martin Reichardt ${ }^{1 \dagger}$, Sébastien Sallard ${ }^{1 \neq}$, Petr Novák ${ }^{1}$, Denis Sheptyakov ${ }^{2 \star}$ \\ and Claire Villevieille ${ }^{1 *}$ \\ ${ }^{1}$ Electrochemisty Laboratory, Paul Scherrer Institute, Villigen, Switzerland, ${ }^{2}$ Laboratory for Neutron Scattering and Imaging, \\ Paul Scherrer Institute, Villigen, Switzerland
}

\section{OPEN ACCESS}

Edited by:

Neeraj Sharma,

University of New South Wales,

Australia

Reviewed by:

Wei Kong Pang

University of Wollongong, Australia

Stephen Hull,

Science and Technology Facilities

Council, United Kingdom

*Correspondence:

Denis Sheptyakov

denis.cheptiakov@psi.ch

Claire Villevieille

claire.villevieille@psi.ch

†These authors have contributed

equally to this work

${ }^{\ddagger}$ Present Address:

Sébastien Sallard,

Flemish Institute for Technological

Research (VITO), Mol, Belgium

Specialty section:

This article was submitted to

Energy Storage,

a section of the journal

Frontiers in Energy Research

Received: 27 March 2018

Accepted: 17 July 2018

Published: 08 August 2018

Citation:

Vitoux L, Reichardt M, Sallard S,

Novák P, Sheptyakov D and Villevieille C (2018) A Cylindrical Cell for Operando Neutron Diffraction of Li-Ion Battery Electrode Materials.

Front. Energy Res. 6:76

doi: 10.3389/fenrg.2018.00076
Neutron diffraction is a powerful technique to localize and quantify lithium in battery electrode materials. However, obtaining high-quality operando neutron diffraction data is challenging because it requires achieving good electrochemical performance while cycling a large amount of active material to ensure optimal signal-to-noise ratio. We have developed a cylindrical cell specifically suited for operando neutron diffraction studies, and used it to investigate the structural changes in the Ni-rich $\mathrm{LiNi}_{0.6} \mathrm{Co}_{0.2} \mathrm{Mn}_{0.2} \mathrm{O}_{2}$ cathode material during cycling between 2.5 and $4.3 \mathrm{~V} \mathrm{vs.} \mathrm{Li}^{+} / \mathrm{Li}$. The cell demonstrates reliable electrochemical performance, even after long-term cycling, and the important crystal structure parameters of the active material, including Li occupancy, could be successfully refined with the Rietveld method using neutron diffraction data collected in operando after appropriate background subtraction.

Keywords: operando neutron diffraction, $\mathrm{Li}$-ion batteries, $\mathrm{LiNi}_{0.6} \mathrm{Co}_{0.2} \mathrm{Mn}_{0.2} \mathrm{O}_{2}$, cylindrical cell, long-term cycling, Rietveld refinement

\section{INTRODUCTION}

With their high energy density and high power, lithium-ion batteries are nowadays the leading technology used in portable devices and have started to enter the market for electric vehicles with success (Tarascon and Armand, 2010; Croguennec and Palacin, 2015). In particular, $\mathrm{LiNi}_{1-x-y} \mathrm{Co}_{x} \mathrm{Mn}_{y} \mathrm{O}_{2}$, referred to as $\mathrm{NCM}$ (or NMC) in the literature, is one of the most promising cathode materials used to enhance battery performance (Robert et al., 2014). NCM combines the advantages of the three transition metals: nickel contributes to the high reversible specific charge, cobalt improves the rate capability, and manganese enhances the structural and thermal stability, particularly at high degrees of delithiation. The electrochemical properties are strongly influenced by the chemical composition of the NCM material (Noh et al., 2013). $\mathrm{LiNi}_{1 / 3} \mathrm{Co}_{1 / 3} \mathrm{Mn}_{1 / 3} \mathrm{O}_{2}$ (NCM111) and $\mathrm{LiNi}_{0.5} \mathrm{Co}_{0.2} \mathrm{Mn}_{0.3} \mathrm{O}_{2}$ (NCM523) have already been implemented in commercial batteries, and research is moving toward Ni-rich and Li-rich materials, which provide high specific charge but still suffer from low cycling stability (Liu et al., 2015; Rozier and Tarascon, 2015; Manthiram et al., 2017; Schipper et al., 2017). To develop these technologies further, we must understand the reaction mechanisms in the cell both at the anode and cathode. In situ/operando powder diffraction is a powerful tool for the identification and to some extent, for quantification of the crystallographic changes occurring in the battery materials during operation; these changes are often the origin of the losses in electrochemical performance (Sharma et al., 2015; Peterson et al., 2017). Neutron powder diffraction, in particular, presents several 
advantages for the study of Li-ion batteries. First, neutron scattering lengths are not correlated to the atomic numbers of the elements. Compared to X-ray powder diffraction, neutron powder diffraction is, thus, more sensitive to light elements in presence of heavier elements, such as transition metals, and enables the localization and quantification of lithium ions in the structure. Moreover, it also facilitates the differentiation of elements with similar atomic numbers, such as the transition metals (for example, $\mathrm{Ni}, \mathrm{Mn}, \mathrm{Co}$, and $\mathrm{Fe}$ ) that usually make up the cathode materials. Finally, neutrons have high penetration depth, which enables the study of the crystallographic changes in the bulk structure of the sample. Unfortunately, a large amount of active material must be exposed to the neutron beam to obtain a sufficiently intense diffraction pattern in a reasonable measurement time. The increase in the amount of active material in an electrochemical cell is often detrimental to its electrochemical performance. Moreover, in in situ/operando measurements, every cell component is exposed to the neutron beam and contributes to the diffraction pattern. In particular, both the separator and the electrolyte usually contain hydrogen, which generates a high background because of its high incoherent scattering cross section, hindering thorough data analysis. The challenge in cell design for operando neutron diffraction is, thus, to obtain high-quality diffraction pattern to enable structural refinements while achieving electrochemical performance similar to that in coin-cell configuration. Commercial 18650-type batteries present excellent electrochemical performance, but the poor signal-to-noise ratio in the diffraction pattern, mainly because of the contributions from the hydrogenated electrolyte and separators, limits the structural information retrievable from Rietveld refinements. Moreover, it narrows the range of study to commercialized batteries, such as $\mathrm{LiFePO}_{4}$ (Rodriguez et al., 2010; Sharma et al., 2010, 2017), $\mathrm{LiCoO}_{2}$ (Dolotko et al., 2012; Senyshyn et al., 2014), and $\mathrm{LiNi}_{1 / 3} \mathrm{Mn}_{1 / 3} \mathrm{Co}_{1 / 3} \mathrm{O}_{2}$ (Alam et al., 2014; Dolotko et al., 2014; Pang et al., 2015; Taminato et al., 2016).

A reasonable alternative, and thus an approach pursued by many, is to design custom-made cells for operando neutron diffraction experiments that mimic the electrochemistry obtained with commercial batteries while allowing advanced materials' investigation. Since the pioneering reports of a custom-made cell for in situ neutron diffraction (Bergstöm et al., 1998; Berg, 2001), several cell designs have been developed to meet the requirements of the neutron diffraction experiments. They can be divided into three categories: coin-type cells, cylindrical roll-over cells, and pouch-type cells.

In coin-type cells, a large amount of loose active material powder is encased in a compartment, which is the only part exposed to the neutron beam. In the first designs, polyetheretherketone (PEEK) polymer (Rosciano et al., 2008; Colin et al., 2010) and aluminum/titanium (Godbole et al., 2013) were used to manufacture the compartment, but these prevented conclusive refinements during cell operation because of high background and strong overlap of the diffraction peaks of the compartment with those of the electroactive materials. Structural information was obtained from diffraction patterns collected in situ at a constant voltage for several hours.
High-quality structural refinements based on the diffraction patterns acquired operando during battery operation were achieved with a similar cell using a $\mathrm{Ti}-\mathrm{Zr}$ alloy, which is transparent to neutrons (Bianchini et al., 2013, 2015). However, the large amount of loose powder was detrimental to the electrochemical performance and resulted in significant polarization, limiting the study to the first few cycles at low rate.

To improve the electrochemical performance, Sharma et al. introduced a roll-over design mimicking the cylindrical 18650type cell, in which the positive electrode, separators, and lithium foil used as the negative electrode are rolled together, put inside a vanadium tube, and sealed with wax (Sharma et al., 2011). The quality of the diffraction patterns compared to those collected using commercial batteries was significantly improved by the use of deuterated electrolytes and vanadium casing, which produces almost no coherent diffraction of neutrons. The structural evolution of several cathode $\left(\mathrm{LiFePO}_{4}\right)$ and anode $\left(\mathrm{MoS}_{2}, \mathrm{Li}_{4} \mathrm{Ti}_{5} \mathrm{O}_{12}\right)$ materials was then investigated using this approach, but only the unit cell parameters and phase fraction could be refined using the Rietveld method on the neutron diffraction patterns (Du et al., 2011; Sharma et al., 2011, 2012; Brant et al., 2014). This design was later adapted by closing a cylindrical cell (quartz or aluminum casing) with Swageloktype metallic current collectors (Roberts et al., 2013; Brant et al., 2016). High cycling rates could successfully be achieved, but structural refinements required long measurement times. Unit cell parameters and atomic coordinates for $\mathrm{LiFePO}_{4}$ and $\mathrm{Li}_{0.18} \mathrm{Sr}_{0.66} \mathrm{Ti}_{0.5} \mathrm{Nb}_{0.5} \mathrm{O}_{3}$ were then refined for the diffraction patterns collected in situ at a constant voltage at specific states of charge. A modified 18650-type battery, adapted with a screw to add the deuterated electrolyte, was later proposed. This design improvement allowed, for the first time, the study of $\mathrm{LiNi}_{0.5} \mathrm{Mn}_{1.5} \mathrm{O}_{4}$ vs. graphite after long-term cycling. This cell showed reliable electrochemical performance at high rates, up to $1 \mathrm{C}$, using a highly loaded cathode (4 $\mathrm{g}$ of materials). Rietveld refinement on the diffraction patterns obtained in the charge and discharge states was possible (Boulet-Roblin et al., 2016, 2017). Owing to this design, Boulet-Roblin et al. successfully determined the amount of Li consumed by surface reactions after 100 cycles by performing Rietveld refinement.

The pouch-cell is the latest design developed for operando neutron diffraction experiments (Liu et al., 2013; Pang and Peterson, 2015) and is increasingly in use thanks to its "easy" construction and flexibility regarding the choice of components (separators and electrodes). As in their commercial equivalents, the cathode, anode, and separators are stacked and wrapped in a propylene-coated aluminum pouch, which is heat-sealed after the addition of the electrolyte. Although they provide relatively good electrochemical performance with higher cycling rates, the polymer-coating of the aluminum pouch generates significant background in the diffraction pattern. The quality of refinements is also affected by the anisotropic absorption of the diffracted beam caused by the non-radial geometry of the cell. To minimize such effects, an annular sample can be simulated by probing a stack with equal width and thickness, or the whole setup can be rotated or oscillated in a sufficiently large range of angles 
normal to the scattering plane, thus averaging out the effects of anisotropy (Pang and Peterson, 2015). Using the first method, the refinement of the cell parameters, lithium content, and oxygen positional parameters with Rietveld method could be carried out for $\mathrm{Li}_{1+x} \mathrm{Mn}_{2} \mathrm{O}_{4}$ (Sharma et al., 2013), $\mathrm{Li}_{4} \mathrm{Ti}_{5} \mathrm{O}_{12}$ (Pang et al., 2014b), $\mathrm{LiNi}_{0.5} \mathrm{Mn}_{1.5} \mathrm{O}_{4}$ (Pang et al., 2014c), and $\mathrm{Li}\left(\mathrm{Ni}_{1 / 3} \mathrm{Mn}_{1 / 3} \mathrm{Fe}_{1 / 3}\right) \mathrm{O}_{2}$ (Pang et al., 2014a).

Based on these previous studies, we opted for a homemade cylindrical cell with optimized design to ensure longterm cycling with reliable electrochemistry and low absorption from the undesirable components located in the beam path (such as the electrolyte, separator, and casing). As a proof of concept, we used operando neutron diffraction to investigate $\mathrm{Li}_{x}\left(\mathrm{Ni}_{0.6} \mathrm{Co}_{0.2} \mathrm{Mn}_{0.2}\right) \mathrm{O}_{2}$ as a cathode material cycled vs. lithium metal $\left(\mathrm{Li}^{+} / \mathrm{Li}\right)$. We follow the evolution of the refined unit cell, as well as of the internal crystal structure parameters, including the atomic coordinates and site occupation for the charge carrier (lithium), during the first charge-discharge cycle of the battery. Additionally, we demonstrate that the cell can achieve long-term cycling stability, and post-mortem scanning electron microscopy (SEM) analysis was carried out on the cathode material, the lithium metal anode, and the separator to reveal a possible cell failure mechanism.

\section{MATERIALS AND METHODS}

\section{Ex Situ and Operando Neutron Diffraction Experiments}

All neutron diffraction experiments were carried out at the HRPT high-resolution powder diffractometer at the SINQ spallation source (PSI) using the high intensity mode with a wavelength of $1.494 \AA$ obtained from the (533) reflection of a Ge vertically focusing monochromator (Fischer et al., 2000) and determined using Si powder standard sample (NIST standard reference material 640d). The instrument is featuring a position-sensitive detector covering a scattering angles range of $160^{\circ}$, and a total solid angle of $\sim 0.1 \mathrm{sr}$. Rietveld refinements were carried out using the Fullprof suite (Rodríguez-Carvajal, 1993).

For the ex situ neutron diffraction experiments, pristine $\mathrm{Li}\left(\mathrm{Ni}_{0.6} \mathrm{Co}_{0.2} \mathrm{Mn}_{0.2}\right) \mathrm{O}_{2}$ powder (NCM622, MTI) (>1g), separator foils, and liquid electrolytes $(2 \mathrm{~mL})$ were measured inside vanadium cylindrical containers $(\varnothing 6 \mathrm{~mm})$ sealed with indium wire. Separator foils, polyvinylidene fluoride (PVDF) film (Goodfellow), PVDF Inmmobilion-P membrane (Merck), polyethylene (Goodfellow), Celgard 2400 (Celgard), and Celgard 2500 (Celgard) were dried prior to the measurement at $60^{\circ} \mathrm{C}$ to remove the water adsorbed at the surface. The standard electrolyte was LP30 $\left(1 \mathrm{M} \mathrm{LiPF}_{6}\right.$ in ethylene carbonate (EC) : dimethyl carbonate (DMC) $50: 50 \mathrm{wt} . \%$ ), and the deuterated electrolyte had the following composition: $1 \mathrm{M}$ in $\mathrm{LiPF}_{6}$ in d-EC:d-DMC (30 : 70 wt.\%).

For the operando neutron diffraction experiments, the electrochemical cell NCM622 : SuperC65 : PVDF (80:10:10 in wt.\%)|1 $1 \mathrm{M} \mathrm{LiPF}_{6}$ in d-EC : d-DMC (50:50)|Li metal was assembled in the cylindrical cell configuration in an argon-filled glovebox. The lithium foil used as the counter electrode $(3 \times$
$13 \mathrm{~cm}$ ) was calendered to $170 \mu \mathrm{m}$ to ensure easy introduction of the stack into the cylindrical cell. For the positive electrode, a mixture of $80 \mathrm{wt} . \%$ of active material (NCM622, MTI), $10 \mathrm{wt} . \%$ of Super C65 (Imerys) as a conducting additive, and $10 \mathrm{wt} . \%$ polyvinylidene fluoride (PVDF, Arkema) as a binder was mixed in $N$-methyl-2-pyrrolidinone (NMP) solvent using a mechanical turbo stirrer and, then, cast with the doctor blade technique onto an aluminum foil, which was used as the current collector. The quantity of active material in the neutron beam was maximized by using double-side coated electrode. The cast slurry was first dried at $80^{\circ} \mathrm{C}$ under vacuum overnight to remove the NMP solvent. The electrode $(3 \times 14 \mathrm{~cm})$ was calendered to a final thickness of $120 \mu \mathrm{m}$ and achieved a loading of ca. $700 \mathrm{mg}$ of active material. The electrode was finally dried overnight at $120^{\circ} \mathrm{C}$ under vacuum prior to its insertion in an argon-filled glovebox. Two Celgard 2500 foils $(3 \times 16 \mathrm{~cm})$ were used as separators and dried overnight at $60^{\circ} \mathrm{C}$ to remove absorbed water before the cell assembly.

To collect neutron diffraction data during cell cycling, the cell was fixed vertically on a dedicated sample holder in the middle of the sample table, which enabled the center of the cylindrical cell to be matched to the optimal beam height. Horizontal and vertical beam reductions were used to avoid unwanted scattering, such as from the parts made of PEEK. The cell was connected directly to a VMP-300 potentiostat (BioLogic) and galvanostatically cycled using $8.5 \mathrm{~mA} / \mathrm{g}$ as specific current $(1 \mathrm{Li}$ reaction in $20 \mathrm{~h}$ using a practical specific charge of $170 \mathrm{mAh} / \mathrm{g}$ ) between 2.5 and $4.3 \mathrm{~V}$ vs. $\mathrm{Li}^{+} / \mathrm{Li}$ at room temperature. The cell voltage was held constant for 3 and $5 \mathrm{~h}$ at $4.3 \mathrm{~V}$ vs. $\mathrm{Li}^{+} / \mathrm{Li}$ and $2.5 \mathrm{~V}$ vs. $\mathrm{Li}^{+} / \mathrm{Li}$, respectively. Neutron diffraction patterns were collected in operando mode, i.e., during cell operation, without any relaxation period. One scan was collected over a period of just less than $2 \mathrm{~min}$, and 32 scans were merged into one pattern, corresponding to ca. $1 \mathrm{~h}$ of counting time, in order to obtain a good signal-to-noise ratio enabling reliable Rietveld refinement. This way, it is possible to control that no significant lattice or phase evolution during the resulting counting time. The applied cycling rate and merging procedure should be optimized for each new experiment. At both cut-off voltages, the scans were merged over the whole duration of the potentiostatic step $\left(3 \mathrm{~h}\right.$ for $4.3 \mathrm{~V}$ vs. $\mathrm{Li}^{+} / \mathrm{Li}$ and $5 \mathrm{~h}$ for $2.5 \mathrm{~V}$ vs. $\mathrm{Li}^{+} / \mathrm{Li}$ ). Subtraction of the substantial background scattering is a rather critical step for successful data treatment and was performed prior to Rietveld analysis. By using normalization on the well isolated broad peaks at low scattering angles, the unwanted scattering from the Celgard could be effectively removed. These diffraction peaks, which do not appear for dry Celgard, are thought to originate from the adsorption of water molecules at the surface of the separator following their wetting with electrolyte. Normalization was done using diffraction data from non-dried Celgard in vanadium can with an air atmosphere. Additionally, the parasitic scattering from the deuterated electrolyte, which yields a few intense broad maxima originating from short-range correlations in the liquid, could be eliminated. Sequential refinements on all 46 diffraction patterns collected during cell operation were done using the Fullprof Suite (Rodríguez-Carvajal, 1993). 


\section{Electrochemical Tests}

For the long-term cycling experiments, the same cylindrical cell configuration as for the neutron diffraction measurements was used, but with standard LP30 electrolyte instead of the deuterated electrolyte. Galvanostatic cycling was undertaken using a $8.5 \mathrm{~mA} / \mathrm{g}$ specific current $(\mathrm{C} / 20$ rate using a practical specific charge of $170 \mathrm{mAh} / \mathrm{g}$ ) between 2.5 and $4.3 \mathrm{~V}$ vs. $\mathrm{Li}^{+} / \mathrm{Li}$ with a $1 \mathrm{~h}$ potentiostatic step at both cut-off voltages.

The electrodes used in the cylindrical cell were also tested vs. lithium metal using the same cycling protocol in a standard type coin-type cell with the standard LP30 electrolyte and glass fiber separators.

\section{Post-mortem Experiments}

SEM measurements were performed with a Carl Zeiss Ultra 55 scanning electron microscope, using the secondary electron detector to emphasize the surface morphology. The images were taken at an acceleration voltage of $3 \mathrm{kV}$ and a working distance of ca. $3 \mathrm{~mm}$ to ensure limited damage of the species formed upon cycling, particularly the polymeric species formed by electrolyte decomposition.

\section{RESULTS AND DISCUSSION Cylindrical Cell Design}

The designed cylindrical cell for operando neutron diffraction experiment is presented in Figure 1.

The design is inspired by the 18650 commercial cells and should reduce the number of unwanted components in the beam path or, if this is not possible, allow the use of materials with low neutron scattering and absorption. In this regard, aluminum has been chosen because of its relatively low cost, ease of machining, and its relatively low neutron absorption, even though coherent diffraction on the aluminum of the cell housing cannot be avoided.

The stack, comprising separator/positive electrode/separator/ negative electrode, was rolled around an inner hollow mandrel made of aluminum $(\varnothing 6 \mathrm{~mm})$ and inserted into the cylindrical aluminum outer casing ( $110 \mathrm{~mm})$. The electrolyte (ca. $1 \mathrm{~mL}$ ) was added on top of the rolled layers before the cell was sealed with a PEEK cap. One separator foil acts as insulator by shielding the roll from the cylindrical outer casing, and the second prevents short circuits by separating the two electrodes. The positive connector is the central part of the mandrel made of aluminum (in agreement with the casing to avoid an additional undesired phase in the beam), while the negative connector, located at the other end of the cylinder, is made of titanium. Both connectors are insulated from each other with PEEK.

All components were tuned to reduce the background in the diffraction pattern (Figure 2). The standard electrolyte LP30 with its high hydrogen content generates a large amount of incoherent scattering, producing a considerable background signal. As highlighted in Figure 2A, using deuterated electrolytes reduces the background by almost a factor of three and is therefore essential for significantly improving the signal-tonoise ratio in operando neutron diffraction experiments using home-made cell designs. The separators are the next source of significant background signal. Several separators were tested, as shown in Figure 2B. PVDF foils and PVDF membrane, as well as polyethylene, have been reported to be better alternatives to the state-of-art Celgard (Brant et al., 2014; Pang and Peterson, 2015). Although in the literature the intensities of the diffraction peaks are normalized per gram of material, we found it more suitable to normalize them according to the actual amounts (in $\mathrm{mm}^{2}$ ) inserted in the neutron diffraction cell. Using this approach, the Celgard foils were found to generate the least background on the neutron diffraction pattern, whereas PVDF foil and membrane produced similarly high backgrounds. Moreover, the PVDF foils and membrane are thicker than Celgard, which limits the number of coils around the mandrel and, thus, the quantity of active material in the beam. Thus, Celgard 2500 was selected as the separator foil for operando neutron diffraction experiments. Kapton tape, which is used as an adhesive to fix the positive electrode and separator foils to the mandrel and maintain the tightness of the electrodes in the roll, was also analyzed. Its background is rather low compared to that produced by the liquid electrolyte and Celgard foil, but the amount should still be kept to a minimum.

The acquisition of neutron diffraction patterns with high signal-to-noise ratio in a relatively short time for structural refinements is, thus, possible with this design.

\section{Operando Neutron Diffraction Experiment Structure of the Pristine Material}

Initially, the crystal structure of the NCM622 pristine material was assessed by ex situ neutron powder diffraction. The result of the Rietveld refinement is presented in Figure 3 and the refined structural parameters are summarized in Table $\mathbf{1}$.

As described in the literature for $\mathrm{Li}\left(\mathrm{Ni}_{x} \mathrm{Co}_{y} \mathrm{Mn}_{z}\right) \mathrm{O}_{2}$ compounds (Yabuuchi and Ohzuku, 2003), the pristine material has an $\alpha-\mathrm{NaFeO}_{2}$-type layered structure (space group $R-3 m$, $\mathrm{N}^{\circ} 166$ ), in which the transition metals (TM) form with oxygen layers of edge-sharing $\mathrm{TMO}_{6}$ octahedra that are stacked along the $c$-axis (Figure 4). Lithium ions intercalate into the octahedral sites between these slabs. In addition, an exchange of lithium and nickel ions between the crystallographic sites $3 a$ and $3 b$ may occur because of the similar ionic radii of $\mathrm{Li}^{+}(0.76 \AA)$ and $\mathrm{Ni}^{2+}(0.69 \AA)$ ions (Shannon, 1976). This phenomenon, usually referred to as cation mixing in the literature, is particularly common for Ni-rich materials $\left(x_{\mathrm{Ni}} \geq 0.5\right)$. According to the literature, this $\mathrm{Li} / \mathrm{Ni}$ exchange depends on the cationic ratio in $\mathrm{Li}\left(\mathrm{Ni}_{x} \mathrm{Co}_{y} \mathrm{Mn}_{z}\right) \mathrm{O}_{2}$, as well as on the synthetic route, and strongly affects the cycling stability (Noh et al., 2013; Yu et al., 2014; Zhao et al., 2017). Based on reasonable assumptions, i.e., the stability of the $\mathrm{Mn}, \mathrm{Co}$, and $\mathrm{O}$ stoichiometry, neutron diffraction appears to be the most reliable experimental technique to investigate and quantify the cation mixing arising from the difference between the coherent scattering lengths of lithium $(-1.90 \mathrm{fm})$ and nickel $(10.3 \mathrm{fm})$ (Sears, 1992). In the pristine material, 3.5\% of lithium ions have been estimated to be exchanged with nickel ions, which is in agreement with previous reports for this compound (Lee et al., 2007) and similar to the values reported for NCM materials with various cationic ratios (Yin et al., 2006; Noh et al., 2013; Yu et al., 2014; Zhao et al., 2017). 
A

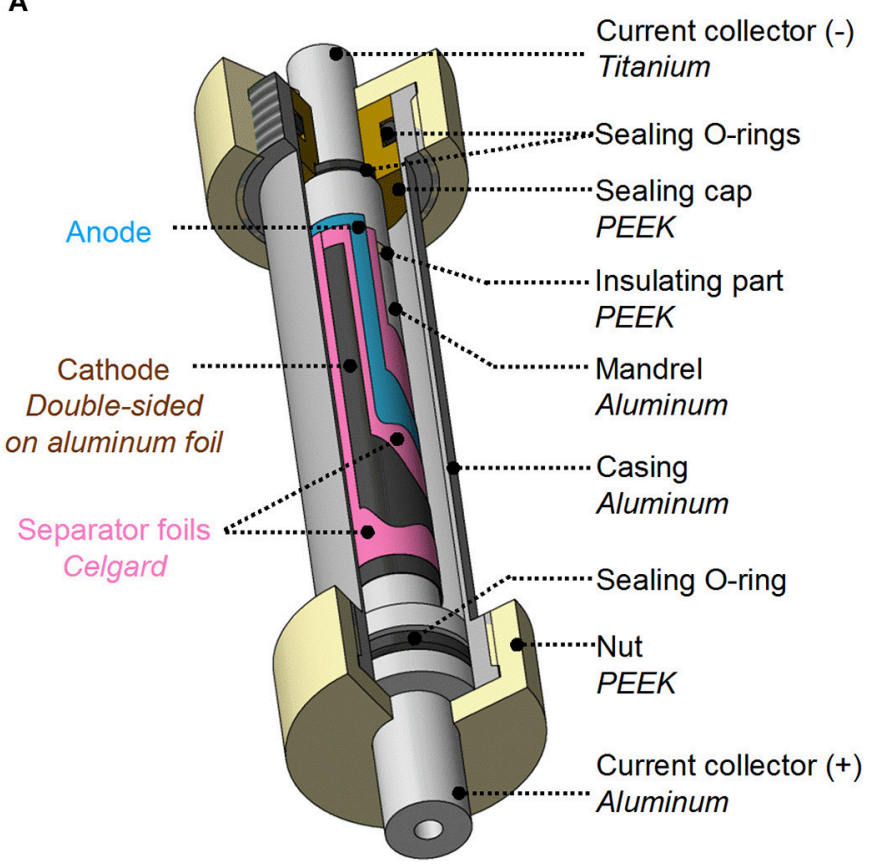

B

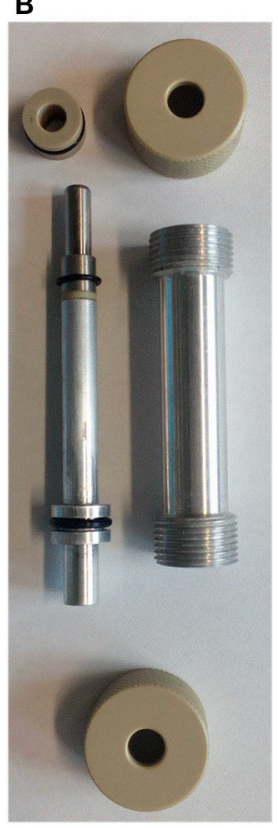

C

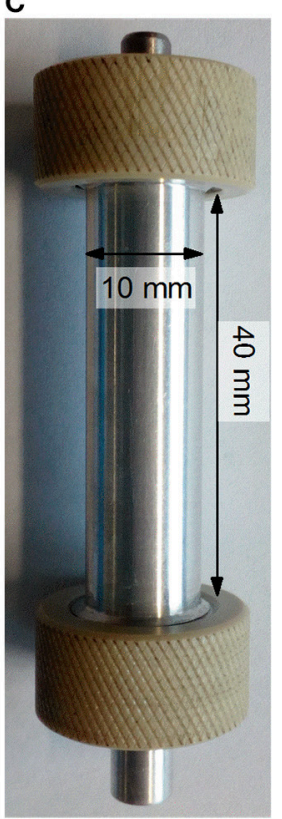

FIGURE 1 | (A) Cylindrical cell design for operando neutron diffraction experiments. (B) Photograph of a dismantled cylindrical cell. (C) Photograph of an assembled cylindrical cell.
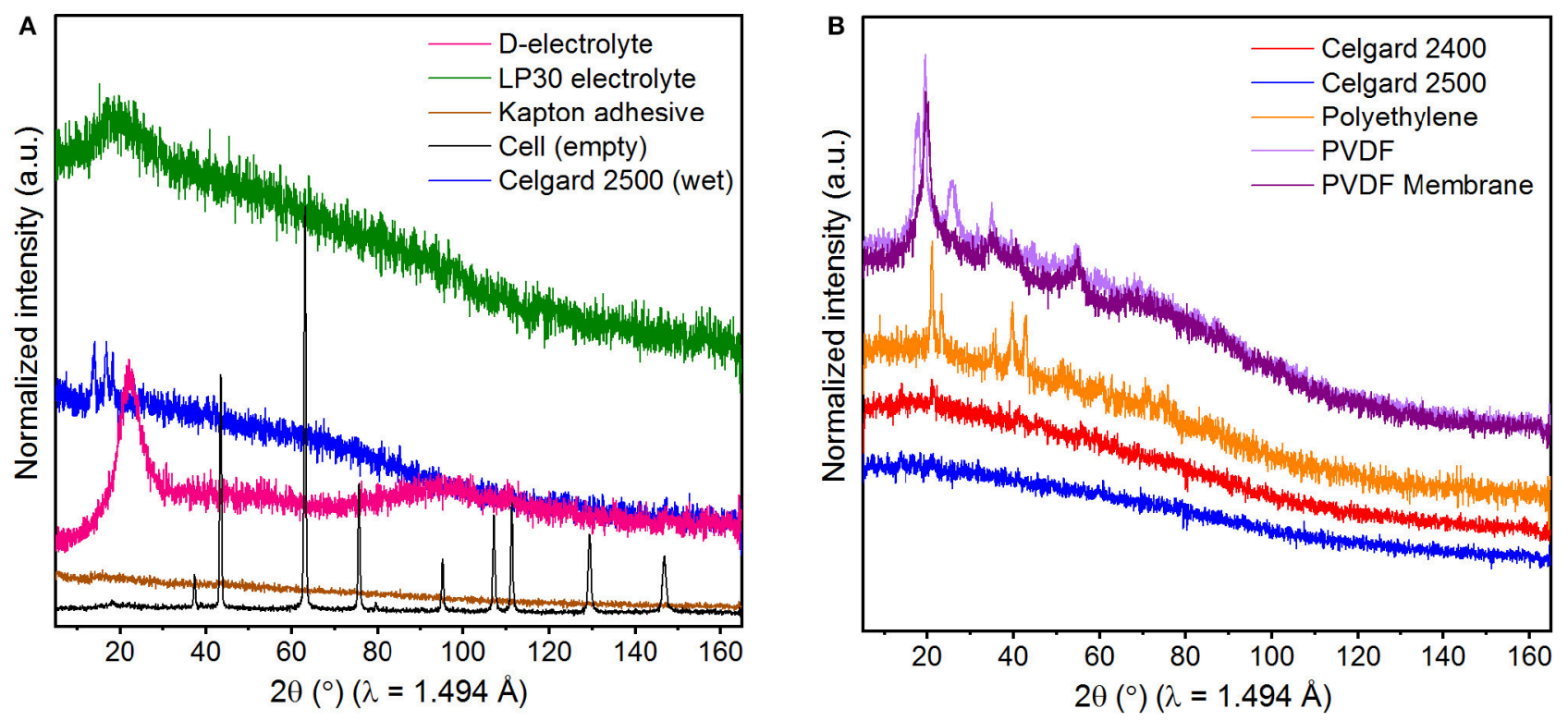

FIGURE 2 | (A) Neutron diffraction patterns of all components of the cylindrical cell (other than cathode and anode). (B) Neutron diffraction patterns of several dry polymeric foils as a possible separator. The intensities are normalized for two separator foils used in the cylindrical cell.

\section{Data Treatment and Refinement Protocol}

The structural evolution of NCM622 during the first cycle was investigated by operando neutron diffraction using the cylindrical cell.
A neutron diffraction pattern measured for $1 \mathrm{~h}$ at ca. $3.7 \mathrm{~V}$ vs. $\mathrm{Li}^{+} / \mathrm{Li}$ during charging is presented as an example in Figure 5A. The achieved signal-to-noise ratio is sufficient to allow the diffraction peaks of the layered material to stand out 


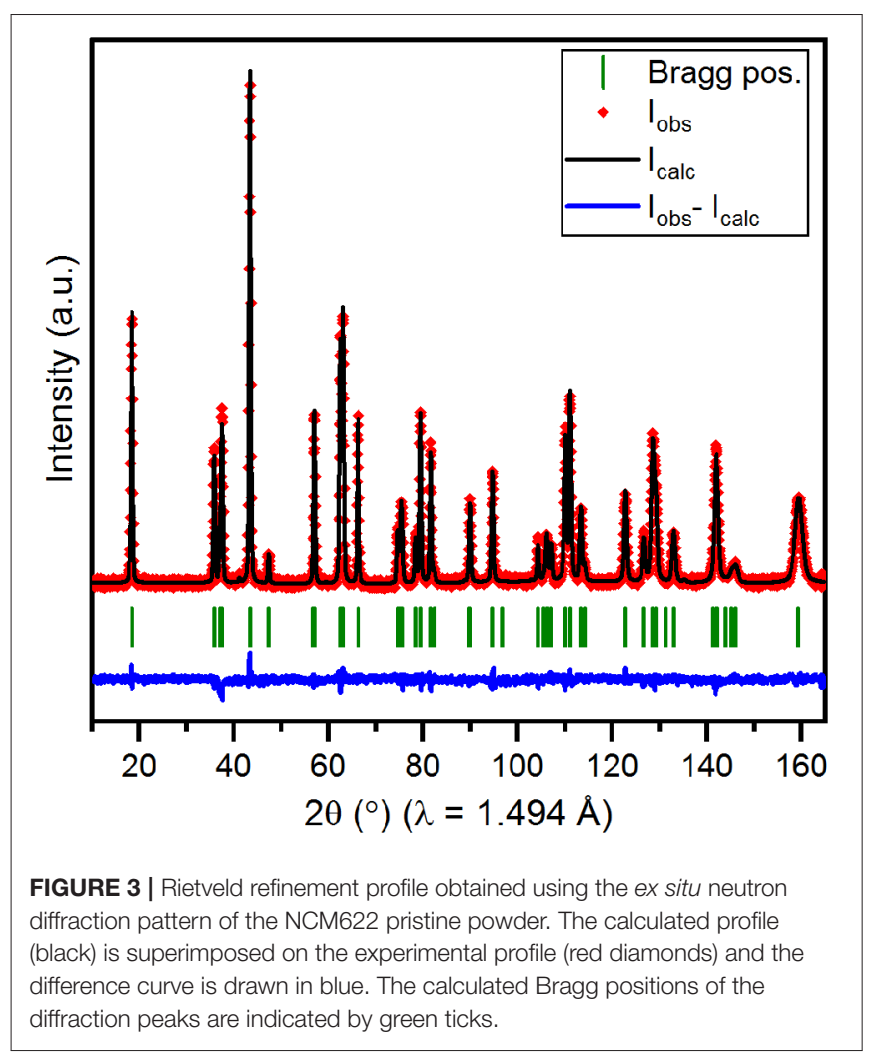

and enables to follow the evolution of the Bragg reflections during lithiation/delithiation. However, the high background generated by the separators and deuterated electrolyte prevented the conclusive refinement of the structural parameters based on the raw data. Both these contributions, which were previously singled out (Figure 2A), were mathematically subtracted from the background of every neutron diffraction pattern. Rietveld refinements could then be successfully carried out. To illustrate the quality of this background subtraction procedure, a corrected pattern collected at ca. $3.7 \mathrm{~V} \mathrm{vs.} \mathrm{Li}^{+} / \mathrm{Li}$ during charge is compared to the raw diffraction pattern in Figure 5A and the Rietveld refinement profile based on this data is presented in Figure 5B.

Three phases were needed to index all Bragg reflections in the background-corrected patterns: NCM622, aluminum (space group $\mathrm{Fm}-3 m, a \approx 4.052 \AA$ ), and lithium metal (space group Im-3m, $a \approx 3.512 \AA$ ). Special care is required for the treatment of the contribution of aluminum from the cell casing because many of the diffraction peaks arising from aluminum overlap with those of NCM622. Thus, data acquisition was carried out on the empty cell (Figure 2) and the diffraction pattern from this machined piece shows severe preferred orientation effects that are challenging to handle quantitatively given the limited number of diffraction peaks in the pattern with the wavelength $\lambda=1.494 \AA$. To take into account the contribution of the strongly textured $\mathrm{Al}$ casing without compromising the precision of the refinement of the main phase of interest, the profile matching mode with constant relative intensities, as implemented in the Fullprof program (Rodríguez-Carvajal, 1993), was used. With this method, the relative peak intensities were calculated during
TABLE 1 | Crystallographic data obtained from the Rietveld refinement using the NCM622 pristine powder neutron diffraction data.

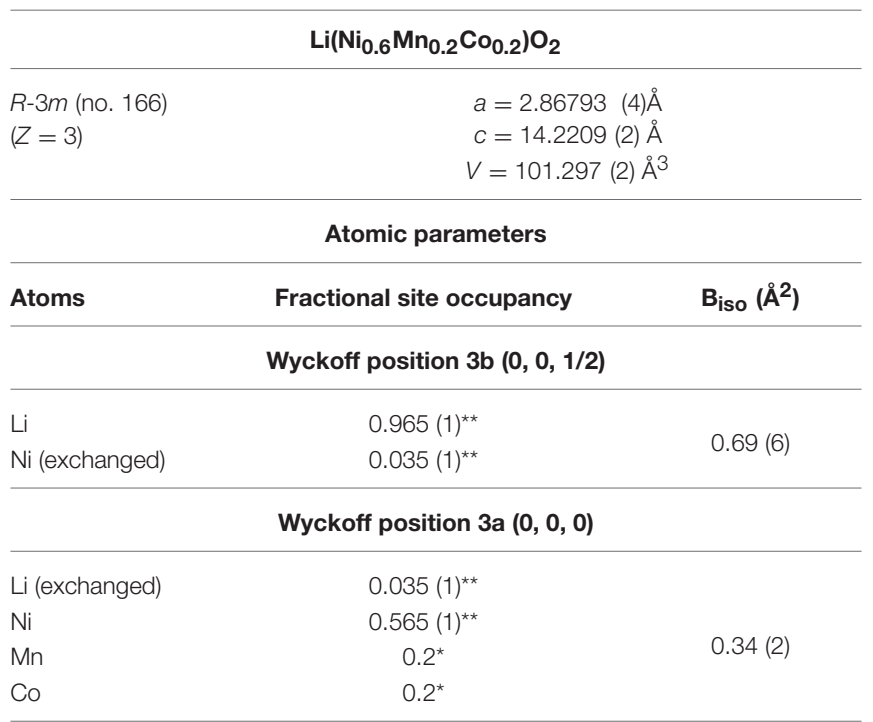

Wyckoff position $6 \mathrm{c}(0,0, \mathrm{z})$

\begin{tabular}{lll}
\hline $\mathrm{O}=0.25885(5)$ & $1.0^{*}$ & $0.75(2)$ \\
\hline
\end{tabular}

\begin{tabular}{lccc}
\hline \multicolumn{4}{c}{ Interatomic distances $(\AA)$} \\
\hline $\mathrm{TM}-\mathrm{O}$ & $1.9656(5)$ & $\mathrm{Li}-\mathrm{O}$ & $2.1119(5)$ \\
\hline
\end{tabular}

\begin{tabular}{lcc}
\hline & Agreement factors \\
\hline$R_{\text {Bragg }}=3.78 \%$ & $R_{f}=2.65 \%$ & $x^{2}=1.36$ \\
\hline
\end{tabular}

Fixed parameters are indicated by "**, and restrained parameters by "***" $\left(\mathrm{OccNN}_{3 a}+\right.$ $\left.\mathrm{OccNi}_{3 b}=0.6, \mathrm{OccLi}_{3 a}+\mathrm{OccLi}_{3 b}=1, \mathrm{OccLi}_{3 a}=\mathrm{OccNi} i_{3 b}\right)$.

the refinement based on the powder diffraction pattern of the empty Al-casing using the profile matching mode. They were then fixed from the Rietveld refinement using the operando neutron diffraction data and only the scale factor was varied for the aluminum phase. This approach showed limitations in two regions of the patterns $\left(2 \theta \approx 63^{\circ}\right.$ and $\left.2 \theta \approx 129^{\circ}\right)$, where peaks arising from the $\mathrm{Al}$ casing coincided with those of both Li metal and NCM622 material. These two regions were, thus, excluded from the sequential refinements. Note that profile matching refinement alone is not a suitable method for treating the empty cell contribution because the peak overlap with the peaks of the NCM622 material is significant throughout the whole diffraction pattern. For the NCM622 layered material, the structural model of the pristine material (Table 1) was used and the following parameters were refined: cell parameters $(a, c)$, two profile peak broadening parameters to account for the microstructure variations of the NCM material, and structural parameters (lithium content in the interslab space (site $3 b$ ) and the oxygen $z$-coordinate). The quantity of $\mathrm{Li} / \mathrm{Ni}$ exchange and atomic displacement parameters $B_{\text {iso }}$ were fixed to the reasonable refined values from the high-quality neutron diffraction data of the pristine powder. Values for instrumental parameters, cell and profile parameters for aluminum and 
lithium, and Gaussian profile parameters for NCM622 were determined during the simultaneous refinement of NCM622 structure at $4.3 \mathrm{~V}$ vs. $\mathrm{Li}^{+} / \mathrm{Li}$ (measured for $3 \mathrm{~h}$ ) and at $2.5 \mathrm{~V}$

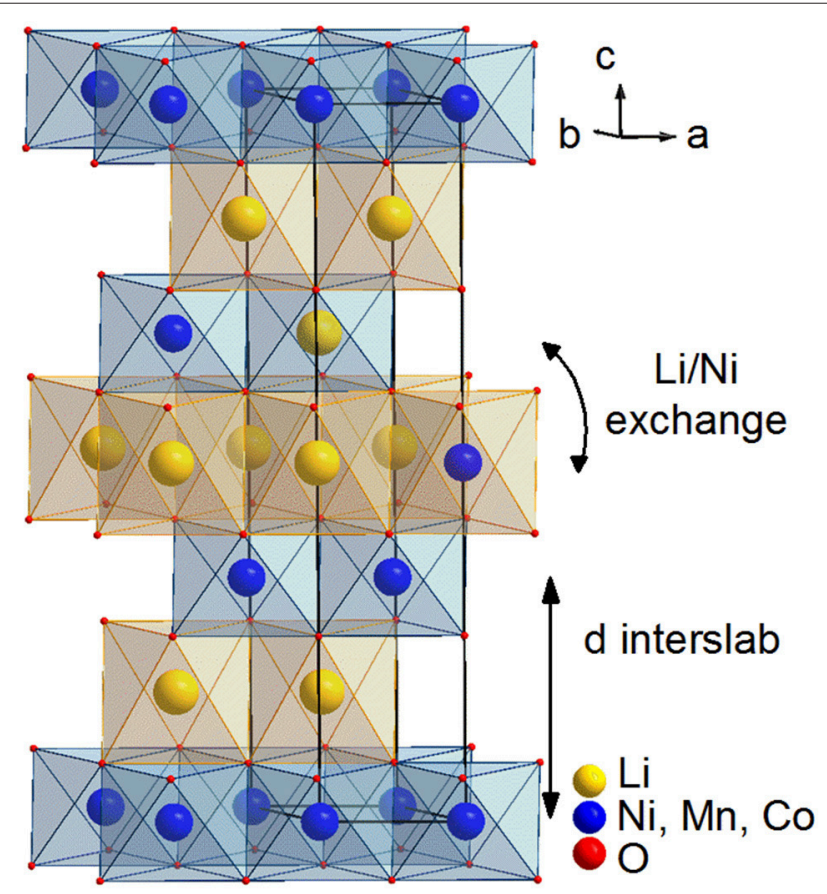

FIGURE 4 | Layered structure of the $\mathrm{Li}\left(\mathrm{Ni}_{0.6} \mathrm{Mn}_{0.2} \mathrm{Co}_{0.2}\right) \mathrm{O}_{2}$ pristine material. vs. $\mathrm{Li}^{+} / \mathrm{Li}$ (measured for $5 \mathrm{~h}$ ) using the Rietveld method. For this combined refinement, every parameter was refined except for the atomic displacement parameters $\left(B_{\text {iso }}\right)$ and the extent of $\mathrm{Li} / \mathrm{Ni}$ exchange, which were fixed to the values of the pristine material.

\section{Evolution of the Crystal Structure Upon Cycling}

A contour plot of the operando neutron diffraction data is presented alongside the electrochemical profile in Figure 6A. Significant crystallographic changes are indicated by the shifting of the NCM622 diffraction lines in the $5-165^{\circ} 2 \theta$ range. Enlargements between $17-19^{\circ}$ and $55.5-69^{\circ}$ in $2 \theta$ are shown in Figure 6B, following, respectively, the evolution of the (003) and (110) reflections. In layered oxides with an $\alpha-\mathrm{NaFeO}_{2}$ structure, the positions of the $(00 l)$ lines are linked to the $c$-axis, i.e. the distance between the transition metal (TM) layers, also known as the interslab distance $\left(d_{\text {interslab }}=c / 3\right)$. The position of the (110) reflection is correlated to the value of the $a$-axis parameter and corresponds to the distance between the transition metals $\left(d_{\mathrm{TM}-\mathrm{TM}}\right)$ (Figure 4).

In addition, the evolution of the unit cell and atomic parameters refined using the Rietveld method during the sequential refinement of operando neutron diffraction data is represented in Figure 7. The R-Bragg factor attests to the reliability of the refinement for each pattern.

The gradual shifting of the diffraction lines reveals a solid solution process during the delithiation and lithiation of the active material and is consistent with the evolution of the refined structural parameters (Figure 7).
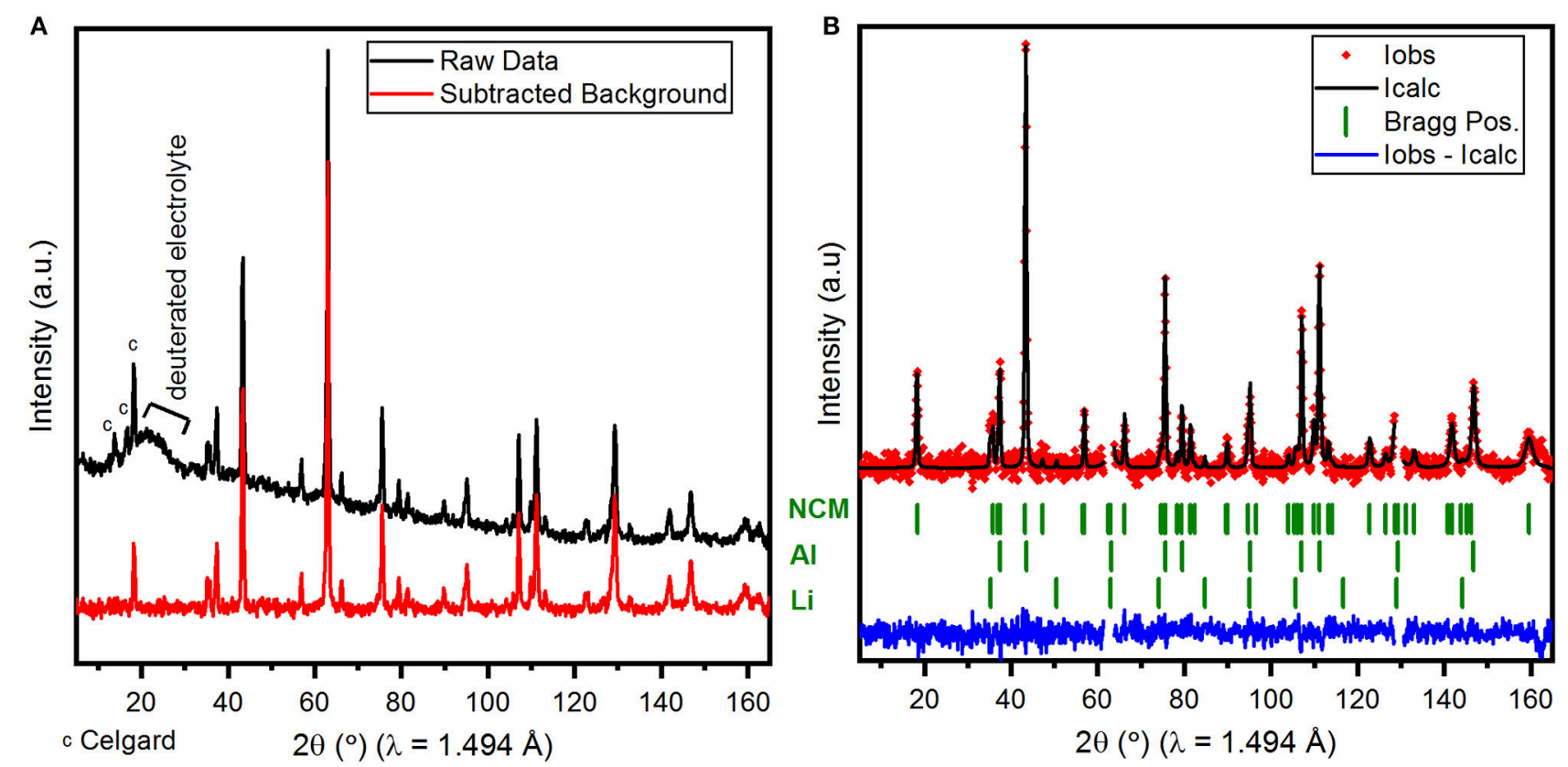

FIGURE 5 | (A) Comparison of a neutron diffraction pattern as collected during the operando experiments (ca. 3.7 V vs. Li+/Li during charge) (black) and after subtraction of the background contributions of the Celgard and deuterated electrolyte (red). (B) Rietveld refinement profile based on this background-subtracted diffraction pattern 


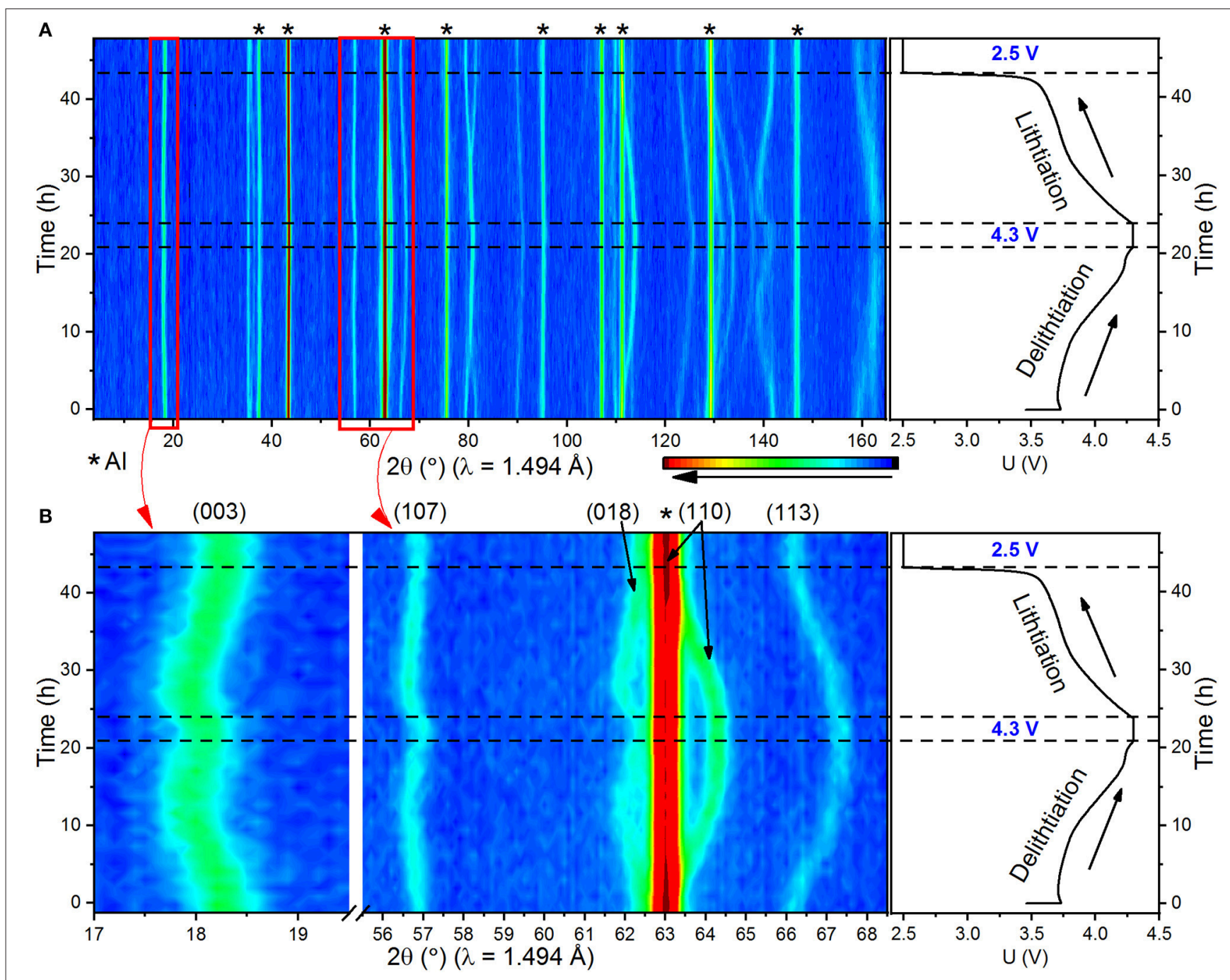

FIGURE 6 | (A) Contour plot representation of the operando neutron diffraction data alongside the electrochemical curve obtained during the cycling of the cylindrical cell with NCM622 as the active material. (B) Enlargements of the contour plot highlight the evolution of (003) and (110) reflections of the active material.

The shifting of the (110) diffraction line toward higher angles is continuous until the cut-off potential, $4.3 \mathrm{~V}$ vs. $\mathrm{Li}^{+} / \mathrm{Li}$. This highlights the reduction in the $a$-axis and, thus, of the in-plane TM-TM distance, from $2.8680(2)$ to $2.8154(3) \AA$. This $1.8 \%$ shrinkage is the result of the oxidation of the $\mathrm{Ni}^{2+} / \mathrm{Ni}^{3+}$ ions to $\mathrm{Ni}^{4+}$, which has a smaller ionic radius. At the same time, the bond between transition metal and oxygen becomes more covalent, as suggested by the decrease of the interatomic distance between the transition metals and oxygen $\left(d_{\mathrm{TM}-\mathrm{O}}\right)$ from $1.964(4)$ to 1.880 (5) $\AA$.

Meanwhile, the shifting of the (003) diffraction line is less straightforward to understand. It first shifts toward lower $2 \theta$ angles indicating an increase in the $c$ cell parameter and, thus, of the interslab distance, starting with $c=14.2208(11) \AA\left(d_{\text {interslab }}\right.$ $\sim 4.740 \AA$ ) at $3.7 \mathrm{~V} \mathrm{vs.} \mathrm{Li}^{+} / \mathrm{Li}$. The latter results from increasing electrostatic repulsion forces between the oxygenated layers when lithium ions are removed from the interslab space (Van der
Ven et al., 1998). However, the highest value for the $c$ cell parameter $\left[c=14.502(3) \AA, d_{\text {interslab }} \sim 4.836 \AA\right.$ ] was reached at $x_{\mathrm{Li}}=0.40(11)$ at ca. $4.0 \mathrm{~V}$ vs. $\mathrm{Li}^{+} / \mathrm{Li}$. Pursuing delithiation, the (003) diffraction line, as well as all other peaks with the $l$ index dominating in their $(h k l)$ Miller indices, shifts slightly back to higher $2 \theta$ angles, and the $c$ cell parameter decreases, reaching $14.383(2) \AA\left(d_{\text {interslab }} \sim 4.794 \AA\right)$ for $x_{\mathrm{Li}} \approx 0.10(10)$ at $4.3 \mathrm{~V}$ vs. $\mathrm{Li}^{+} / \mathrm{Li}$. This behavior has been reported for layered $\mathrm{Li}_{x} \mathrm{NiO}_{2}$ (Li et al., 1993), $\mathrm{Li}_{x} \mathrm{CoO}_{2}$ (Ohzuku and Ueda, 1994; Amatucci et al., 1996), and $\mathrm{Li}_{x}(\mathrm{Ni}, \mathrm{Co}, \mathrm{Mn}) \mathrm{O}_{2}$ materials (Alam et al., 2014; Ishidzu et al., 2016; Kondrakov et al., 2017b) and its origin is still under debate. A theoretical investigation of the $\mathrm{LiCoO}_{2}$ phase diagram (Van der Ven et al., 1998) suggested that a strong overlap of the $2 p$ orbitals of oxygen and the partially filled $e_{g}$ orbitals of the transition metal would lead to charge transfer, resulting in the depletion of the oxygen charge. The decrease in electrostatic repulsions between oxygenated 

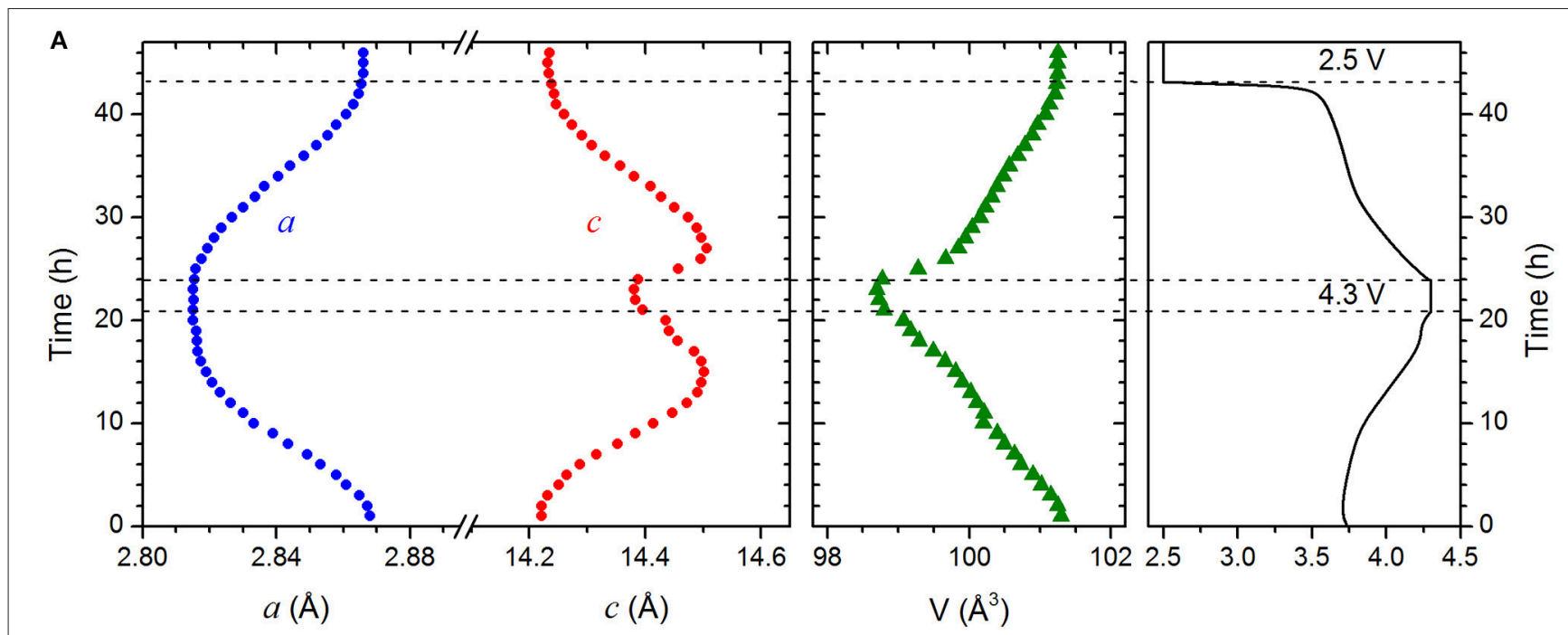

B
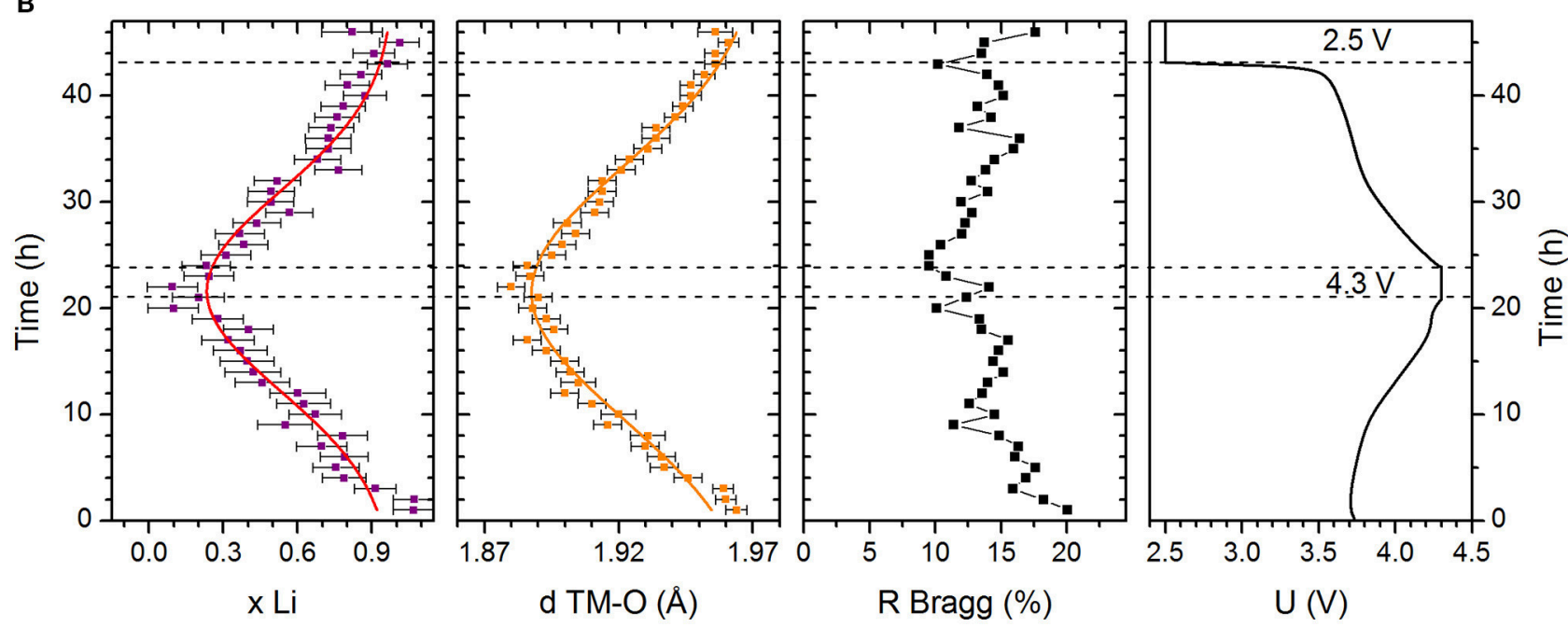

FIGURE 7 | Evolution of the structural parameters of NCM622 determined from the sequential refinement using neutron diffraction data collected during the operando experiments. (A) Unit cell parameters and volume. The errors on these values are smaller than the symbol sizes. (B) Lithium content and the interatomic distance between oxygen and transition metal atoms $\left(d_{\mathrm{TM}-\mathrm{O}}\right)$. Solid lines in these panels are guides to eye. The reliability factor, R-Bragg, is indicated for each refinement. The standard deviations of the refined parameters for the refinements done on the background-subtracted data have been corrected to account for the artificial underestimation of the errors, see text for details.

layers would then lead to the collapse of the interlayer space. This model was experimentally and theoretically confirmed for $\mathrm{Li}_{x} \mathrm{Ni}_{0.8} \mathrm{Co}_{0.1} \mathrm{Mn}_{0.1} \mathrm{O}_{2}$ (Kondrakov et al., 2017a). According to in situ X-ray powder diffraction experiments (Yoon et al., 2006; Ghanty et al., 2015), it could also be linked to the formation of a second hexagonal phase at high voltage, as it has been shown for $\mathrm{LiNiO}_{2}$ ( $\mathrm{Li}$ et al., 1993). This second phase is isostructural with the pristine material but has a shorter $a$-axis, longer $c$-axis, and significantly lower lithium content. This mechanism would induce a splitting or broadening of the diffraction peaks, which is not observed in our experiment. The hypothesis of variations in the coulombic repulsion between oxygenated layers with lithium content is, thus, favorable in our case.
The evolution of the $a$ and $c$ cell parameters results in a continuous shrinkage of the unit cell volume upon delithiation, from $101.299(11) \AA^{3}$ at $3.7 \mathrm{~V}$ vs. $\mathrm{Li}^{+} / \mathrm{Li}$ to $98.73(2) \AA^{3}$ at $4.3 \mathrm{~V}$ vs. $\mathrm{Li}^{+} / \mathrm{Li}$. This volume variation $(2.5 \%)$ is in agreement with the literature values (Kondrakov et al., 2017a). It has been shown to vary linearly with the nickel content in NCM materials and result in the degradation of the Ni-rich cathode material (Noh et al., 2013; Ishidzu et al., 2016; Kim et al., 2016; Kondrakov et al., 2017b).

Operando neutron diffraction was performed consecutively during the discharge of the cell, i.e., lithiation of the NCM622 material, and shows that the structural changes previously described for delithiation are reversible. Indeed, the intercalation of lithium between the layers first leads to an increase in the 

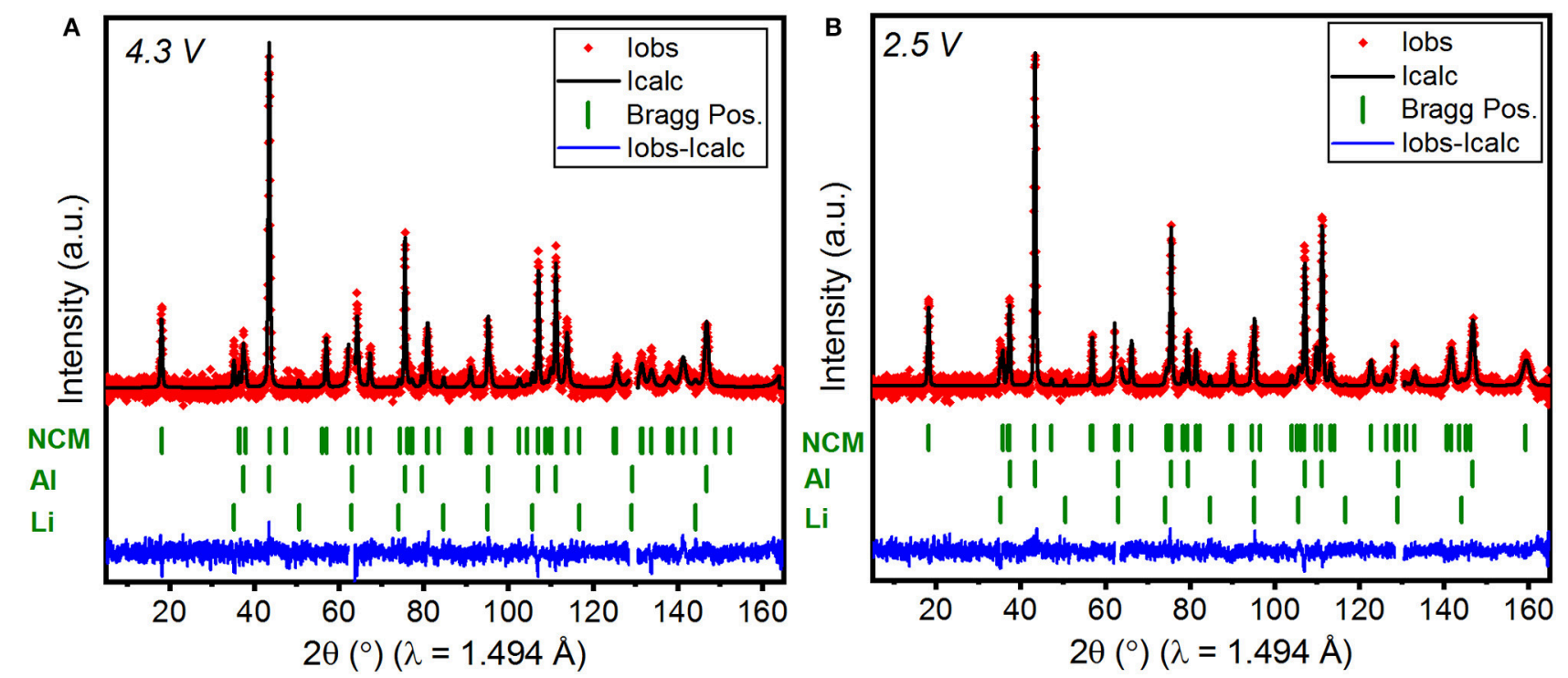

FIGURE 8 | Rietveld refinements profiles obtained using neutron diffraction data collected at constant voltage. (A) At $4.3 \mathrm{~V}$ for $3 \mathrm{~h}$ and (B) at $2.5 \mathrm{~V}$ for $5 \mathrm{~h}$. Both refinements feature two excluded regions, as discussed in the text.

TABLE 2 | Refined crystal structure parameters obtained from the Rietveld refinement using the background-corrected neutron diffraction data collected at constant voltage $(\mathrm{CV})$, in operando $(\mathrm{O})$, and for the pristine powder (values taken from Table 1).

\begin{tabular}{lccccc}
\hline & $\mathbf{4 . 3} \mathbf{V}(\mathbf{C V})$ & $\mathbf{4 . 3} \mathbf{V}(\mathbf{O})$ & $\mathbf{2 . 5} \mathbf{V}(\mathbf{C V})$ & $\mathbf{2 . 5} \mathbf{V}(\mathbf{O})$ & Pristine \\
\hline $\mathrm{l}(\AA)$ & $2.8151(3)$ & $2.8154(2)$ & $2.8656(3)$ & $2.8661(2)$ & $2.86793(4)$ \\
$\mathrm{C}(\AA)$ & $14.376(2)$ & $14.383(2)$ & $14.2364(12)$ & $14.232(1)$ & $14.2209(2)$ \\
$V\left(\AA^{3}\right)$ & $98.66(2)$ & $98.73(2)$ & $101.245(15)$ & $101.25(2)$ & $101.297(2)$ \\
\hline$x_{\mathrm{Li}}$ & $0.09(10)$ & $0.09(10)$ & $0.96(6)$ & $1.01(8)$ & $0.965(1)$ \\
$z_{\mathrm{O}}$ & $0.2671(8)$ & $0.2676(8)$ & $0.2596(4)$ & $0.2593(5)$ & $0.25885(5)$ \\
$d_{\mathrm{TM}-\mathrm{O}}(\AA)$ & $1.884(5)$ & $1.880(5)$ & $1.959(3)$ & $1.961(4)$ & $1.9656(5)$ \\
$d_{\mathrm{Li}-\mathrm{O}}(\AA)$ & $2.173(8)$ & $2.179(8)$ & $2.118(4)$ & $2.117(5)$ & $2.1119(5)$ \\
\hline $\mathrm{R}_{\mathrm{Bragg}}(\%)$ & 10.8 & 14.13 & 11.6 & 13.7 & 3.78 \\
$\chi^{2}$ & 1.07 & 0.84 & 1.07 & 0.82 & 1.36 \\
\hline
\end{tabular}

The standard deviations of the refined parameters for the refinements done on the background-corrected data have been corrected to account for the artificial underestimation of the errors, see text for details.

$c$ cell parameter, which then continuously decreases until $2.5 \mathrm{~V}$ vs. $\mathrm{Li}^{+} / \mathrm{Li}$ because of the screening effect of the lithium ions on the electrostatic repulsion forces between the oxygenated layers. As expected the $a$ cell parameter increases because of the increase of TM-TM distance induced by the larger ionic radii of nickel ions in a reduced state; in addition, the interatomic distance, $d_{\mathrm{TM}-\mathrm{O}}$, increases. Moreover, the structure of NCM622 at $2.5 \mathrm{~V}$ vs. $\mathrm{Li}^{+} / \mathrm{Li}$ after the first cycle is very close to the structure of the material at $3.7 \mathrm{~V}$ vs. $\mathrm{Li}^{+} / \mathrm{Li}$ at the beginning of cycling.

To complete the study, the voltage was held constant for 3 and $5 \mathrm{~h}$ at cut-off potentials of 4.3 and $2.5 \mathrm{~V}$ vs. $\mathrm{Li}^{+} / \mathrm{Li}$, respectively.
The corresponding Rietveld refinement profiles are presented Figure 8. The refined structural parameters are summarized in Table 2 and compared to the structural parameters obtained from the Rietveld refinements on neutron diffraction data collected in operando and for the pristine powder. The results of refinements from the datasets collected in the cell, at constant voltage (CV), and in operando $(\mathrm{O})$, were in fact obtained on the backgroundcorrected data: the contributions from the Celgard separator and from the deuterated electrolyte were subtracted prior to the refinements. This subtraction procedure inevitably led to substantially higher variances of the background-subtracted data. This, in turn, has led to the smaller weights of the point-bypoint calculated squared differences between the "experimental" and the calculated intensities, entering the calculation of $\chi^{2}$, and thus, to unrealistically low values of the $\chi^{2}$ values. In this respect, these unusually low $\chi^{2}$ values are a consequence of the higher intensity variances than these would be expected for the directly measured intensities of the same magnitudes. The exact absolute $\chi^{2}$ values in Table 2 are therefore irrelevant characteristics of the refinement quality, and should be considered as relative refinement quality indicators only. On the other hand, special care needs to be taken of the errors of the refined parameters, when statistics of the data used for the refinements is modified during data reduction, as it is the case with our operando data. Rietveld refinement code of Fullprof uses the value of the reduced chi-squared $\chi_{v}^{2}=\frac{\chi^{2}}{n-p}$, where $n-p$ is the number of degrees of freedom of the refinement problem (RodríguezCarvajal, 1993), to additionally correct the standard deviations of the refined parameters, in a way that the estimated standard deviations are multiplied by the $\sqrt{\chi_{v}^{2}}$. This is why, in the refinements of our operando data characterized by the unusually low $\chi^{2}$ values because of the background subtraction done in advance, the directly output standard deviations of the 

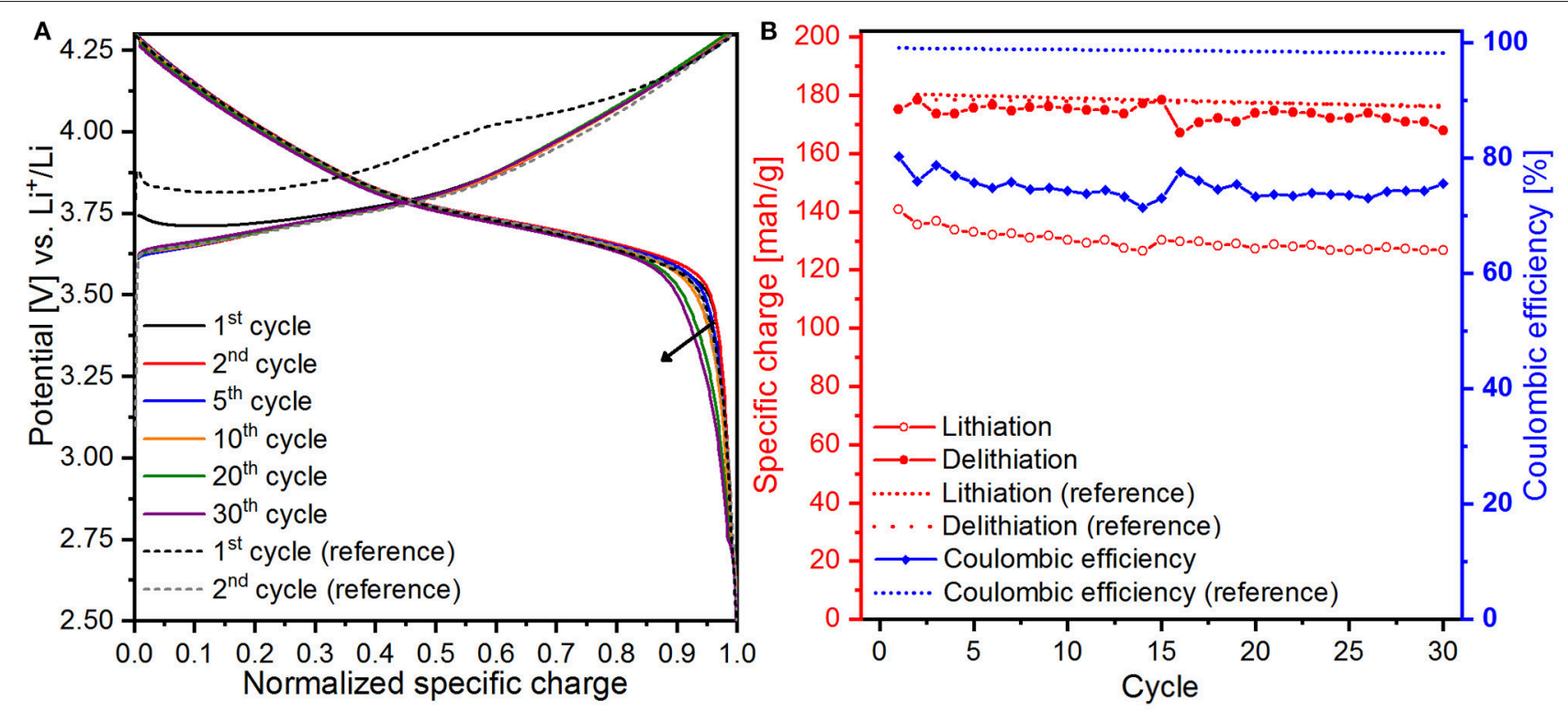

FIGURE 9 | (A) Normalized galvanostatic curves and (B) evolution of the specific charge and coulombic efficiency from the cycling of NCM622 in the cylindrical cell and in standard-type coin cell (reference) for 65 cycles. For clarity, only the linear fit of the reference set of data is represented.

refined parameters would all be underestimated by a factor $\sqrt{\frac{\chi_{\text {our }}^{2}}{\chi_{\text {hypoth }}^{2}}}, \chi_{\text {our }}^{2}$ and $\chi_{\text {hypoth }}^{2}$ being the chi-squared values for "our" refinement on the background-subtracted data, and for the "hypothetical" refinement with exactly the same model on the data with original, unperturbed counting statistics. In order to evaluate this underestimation factor for the standard deviations of the refined parameters from our operando data, and to correspondingly correct for it, we consider the exact formulation for calculation of the $\chi^{2}$ values used in Fullprof: $\chi^{2}=\sum_{i=1}^{n} w_{i}\left\{y_{i, \exp }-y_{i, c a l c}\right\}^{2}$, with the point-by-point calculated weights of the profile points' contributions $w_{i}=\frac{1}{\sigma_{i}^{2}}$. It is thus logical to estimate the artificial reduction factor for errors of refined parameter as $\sqrt{\sum_{i=1}^{n} \frac{1}{\sigma_{i, \text { our }}^{2}} / \sum_{i=1}^{n} \frac{1}{\sigma_{i, \text { orig }}^{2}}}$, with $\sigma_{i, \text { our }}^{2}$ and $\sigma_{i, \text { orig }}^{2}$ being the point-by-point variances of "our", backgroundcorrected, and of the "original", measured data. We have calculated these underestimation factors, and these amount for the 46 patterns we were refining between $\sqrt{1 / 1.42}$ and $\sqrt{1 / 1.44}$. Thus, the strongest underestimation of the errors of the refined parameters as provided directly by the refinement program is most probably by a factor of 1.2. In order to stay on the safe side, we have decided to "back-correct" these output errors for the refinements done on the background-corrected data (operando) by multiplying them all by a more conservative value of 1.3 .

Refinement of the structure using the neutron diffraction data collected for $3 \mathrm{~h}$ at $4.3 \mathrm{~V}$ vs. $\mathrm{Li}^{+} / \mathrm{Li}$ confirms that the delithiation of the layered phase is almost complete at $4.3 \mathrm{~V}$ vs. $\mathrm{Li}^{+} / \mathrm{Li}$ with the $\mathrm{Li}$ content estimated to be $0.09(10)$ at the $3 b$ site, in good agreement with the value deduced from electrochemical measurements $(x \approx 0.08)$. After the discharge of the cell to $2.5 \mathrm{~V}$ vs. $\mathrm{Li}^{+} / \mathrm{Li}, \mathrm{NCM} 622$ is again fully lithiated according to the refinement on the neutron diffraction data collected at a constant voltage. Moreover, the structural parameters of the material NCM622 at this voltage are similar to those of the pristine material, which attests to the reversibility of the delithiation process.

Notably, the values for unit cell parameters and atomic parameters obtained from the refinement on neutron diffraction data acquired in operando mode and at a constant voltage at both cut-off voltages are very similar. The difference lies in the reliability of the refinement, as shown by the RBragg and R-f factors, which are, as expected, better for refinements using neutron data collected for longer periods at a constant voltage. This suggests, nevertheless, that longer acquisitions $(>1 \mathrm{~h})$ are not essential for the monitoring of the crystallographic changes upon lithiation and delithiation with this cylindrical cell design, given adequate data treatment. Moreover, the reasonable evolution of the structural parameters upon cycling (Figure 7) and the similar values obtained for operando and ex situ (pristine) measurements attest to the validity of the Rietveld refinement using operando neutron diffraction data. However, quantitative results concerning the atomic parameters and, in particular, the exact $\mathrm{Li}$ occupation should be considered with care because several parameters were fixed during the Rietveld refinement, including the atomic displacement parameters $\left(B_{\text {iso }}\right)$ and the $\mathrm{Li} / \mathrm{Ni}$ mixing ratio, which can evolve during delithiation and lithiation. For precise structural determination, operando experiments should, as far as possible, be complemented with ex situ neutron diffraction at different states of charge. 

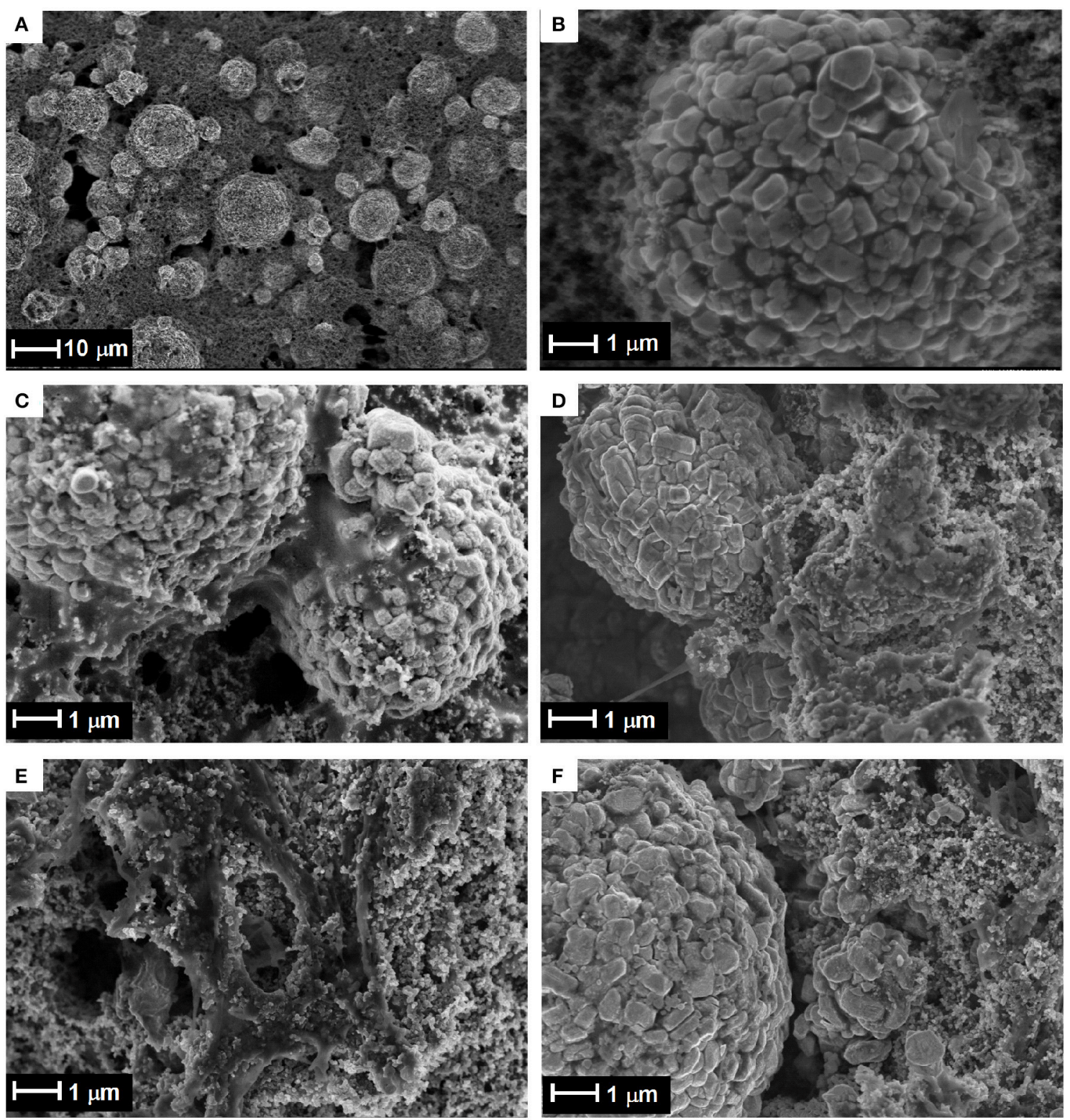

FIGURE 10 | Scanning electron microscopy images of (A) pristine material and (B) a sample taken from the center of the electrode after 65 cycles, (C) unwashed electrode and (D) washed electrode with DMC, and a sample taken from the edge of the electrode, (E) unwashed and (F) washed with DMC.

\section{Electrochemical Performance}

An added value of the designed cell is that it can deliver reliable electrochemical performance upon long-term cycling. The electrochemical performance obtained in the cylindrical cell was compared to the reference values deduced from the cycling under identical conditions of the same material in a standard coin-type cell (Figure 9).

The normalized galvanostatic curves obtained in the cylindrical cell are presented in Figure 9A and compared to the 1st and 2nd normalized galvanostatic curves from the cycling of NCM622 in a standard coin-type cell. The similar shape of the galvanostatic curves from both designs confirms that the same electrochemical behavior occurs. Starting from the 20th cycle, small polarization effects appear at the end of the lithiation from 0.9 to 1.0 in normalized specific charge. There are several sources of this phenomenon, such as irregular current density distribution on the electrode surface or the formation of a thick surface layer on the cathode/separator, which increases the apparent internal resistance of the cell and reduces the diffusion. It could also be linked to the degradation of the NCM622 cathode, as previously reported (Liu et al., 2015; Choi and Aurbach, 2016).

The evolution of the specific charge and the coulombic efficiency is presented in Figure 9B. A high cycling stability 

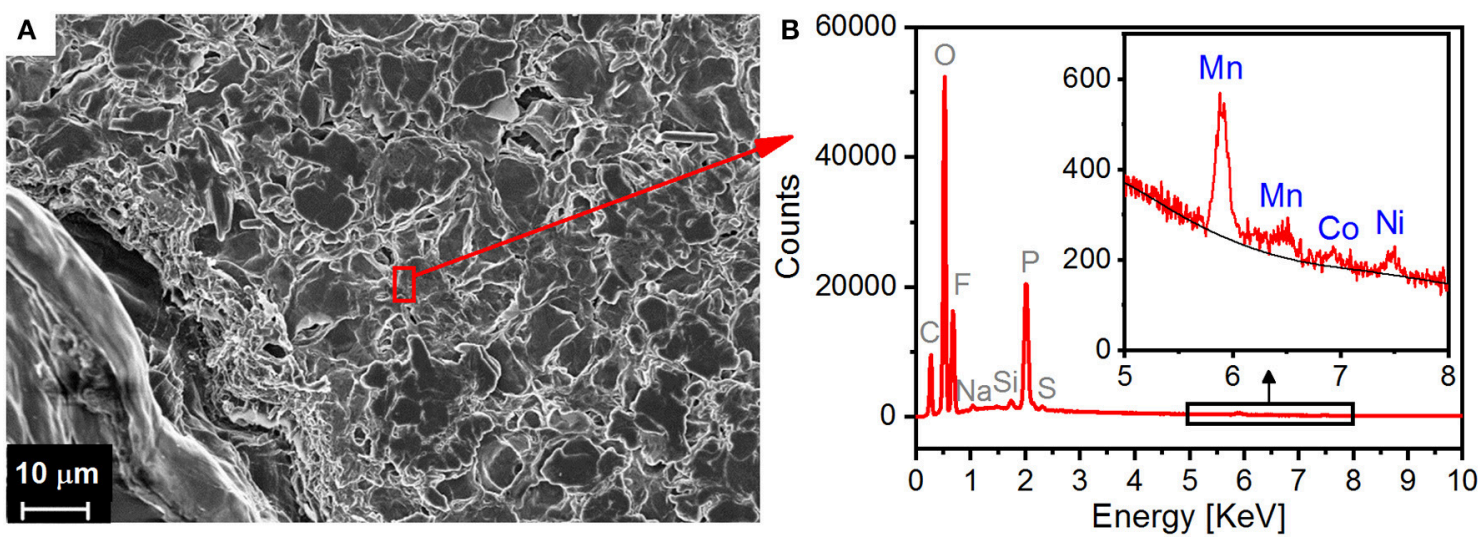

FIGURE 11 | (A) SEM image of cycled lithium anode (center) from the cylindrical cell and (B) EDX spectrum of the surface of the lithium anode after 65 cycles.
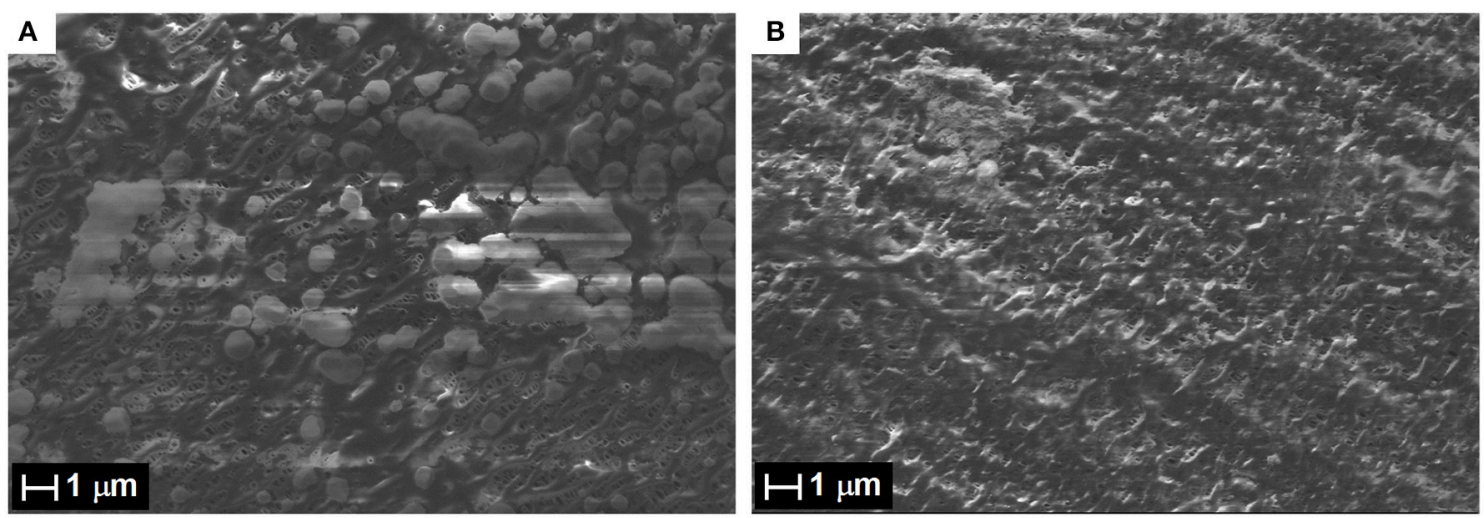

FIGURE 12 | SEM image of the cycled Celgard separators (facing the cathode) of the cylindrical neutron powder diffraction Li-ion cell after 65 cycles: (A) unwashed foil and $\mathbf{( B )}$ foil washed with DMC.

was achieved in the standard cell, having a specific charge of ca. $180 \mathrm{mAh} / \mathrm{g}$ after the first cycle (195 mAh/g) and a stable coulombic efficiency close to $98-99 \%$. The specific charge values obtained from cycling in the cylindrical cell during the delithiation process are very close to the reference values, approximately $175 \mathrm{mAh} / \mathrm{g}$ for the first 30 cycles. Lower specific charge values were obtained during the lithiation, from 140 $\mathrm{mAh} / \mathrm{g}$ at the first cycle to $127 \mathrm{mAh} / \mathrm{g}$ at the 30th cycle. This results in a coulombic efficiency fluctuating around $80 \%$. After 30 cycles, the specific charge values during delithiation dropped, whereas they remained relatively constant during lithiation, resulting in an increase in the coulombic efficiency. These fluctuations are thought to originate from the assembly of the cylindrical cell. First, the inner pressure inside the cell, as well as the quality of electrical contacts with the current collectors, depends on the tightness of the roll, which can be difficult to control because the rolling is manual. Secondly, the inhomogeneous wettability of the electrodes and separators, along with the irregular inner pressure between the electrodes, could cause an irregular current density distribution over the electrode surface, as mentioned previously. In light of these observations, further optimization of the design would increase the tightness between the electrodes during the hand-rolling. The homogeneity of the wettability of the separators and electrodes could possibly be improved by adding electrolyte during rolling or by using pre-wetted separators, even though it would increase the risk of short-circuits during the assembly of the cell. Also, higher charge on delithiation could be a signature of enhanced electrolyte decomposition or, more generally, of parasitic oxidative processes.

\section{Post-mortem Analysis}

Post-mortem analysis using scanning electron microscopy (SEM) coupled with energy-dispersive X-ray spectroscopy (EDX) was performed after long-term cycling (65 cycles) on the cathode, anode and Celgard. Samples were taken from different areas of the electrodes (edges or center) to check possible inhomogeneous reactions and/or gradients. As shown in Figures 10A,B, there were no significant microscale changes in the shape and morphology of the electrode after long-term cycling, which is in agreement with the small volume change estimated from the Rietveld refinement. However, a polymeric-like film, 
attributed to the solid permeable interphase (i.e., electrolyte decomposition products; Edström et al., 2004), was detected at the surface of the unwashed electrode and, especially, at the grain boundaries (Figure 10C). It can be noted that this layer is more pronounced for samples taken from the edge of the electrode (Figure 10E). This inhomogeneity supports the hypothesis discussed above of an irregular current density distribution and parasitic oxidation reactions, which could explain the fluctuating coulombic efficiency and the appearance of polarization effects in the galvanostatic curves after 20 cycles (Figure 9). Additionally, the surface of the aged NCM622 primary particles appears rougher with a small amount of chipping at the edges (Figures 10D-F), which could be attributed to surface degradation associated with the transition metal dissolution. This hypothesis is supported by the detection at the surface of the lithium metal anode of manganese, as well as, to a lesser extent, nickel and cobalt (Figure 11). Transition metal dissolution is detrimental to the electrochemical performance (Choi and Manthiram, 2006; Zheng et al., 2012) because it enhances the development of the solid electrolyte interphase (SEI) at the surface of the negative electrode (here, Li metal), resulting in an increased resistance that hinders the lithium diffusion. The same effect can be generated by the clogging of the separators pores caused by side-products of the electrolyte decomposition (Sharabi et al., 2012). It can indeed be seen in Figure $\mathbf{1 2}$ that a polymer-like film, as well as small agglomerates, covers the surface of the Celgard separator after cycling. A higher resistance arising from the electrolyte decomposition coupled to the transition metal dissolution and clogging of the separator pores could explain the overall decrease of the specific charge in delithiation that is observed during the cycling in the cylindrical cell (Figure 9). However, it is important to note that such effects explain the deviation of the observed electrochemical data in the cell designed for neutron diffraction but do not diminish the quality of the structural refinement.

\section{CONCLUSION}

The design of the cylindrical cell developed for operando neutron diffraction has been validated by monitoring the changes in the crystal structure parameters of $\mathrm{Li}_{x}\left(\mathrm{Ni}_{0.6} \mathrm{Mn}_{0.2} \mathrm{Co}_{0.2}\right) \mathrm{O}_{2}$, which were found to be in good agreement with the literature values. A good signal-to-noise ratio in the diffraction patterns was

\section{REFERENCES}

Alam, M., Hanley, T., Pang, W. K., Peterson, V. K., and Sharma, N. (2014). Comparison of the so-called CGR and NCR cathodes in commercial lithiumion batteries using in situ neutron powder diffraction. Powder Diffr. 29, S35S39. doi: 10.1017/S088571561400102X

Amatucci, G. G., Tarascon, J. M., and Klein, L. C. (1996). $\mathrm{CoO}_{2}$, the end member of the $\mathrm{Li}_{x} \mathrm{CoO}_{2}$ solid solution. J. Electrochem. Soc. 143, 1114-1123. doi: 10.1149/1.1836594

Berg, H. (2001). The LiMn2O4 to $\lambda$-MnO2 phase transition studied by in situ neutron diffraction. Solid State Ion 144, 65-69. doi: 10.1016/S0167-2738(01)00894-3 achieved, enhanced by appropriate background subtraction; thus, the refinement of the unit cell, as well as atomic parameters (with reasonable constraints), was successfully carried out on the neutron diffraction data acquired in operando mode. However, the reliability of the Rietveld refinement based solely on the operando data may not always be sufficient to extract precise quantitative results because of the limited statistics and assumptions used for the constraints. It is, therefore, recommended to complement the operando measurements with in situ experiments (keeping the cell at a certain voltage for the acquisition of better statistics, as presented in this study) or by ex situ experiments on extracted materials at key points of the galvanostatic curve. Electrochemical tests proved that this cylindrical cell is suitable for the investigation of the structural changes in the active material after long-term cycling. Postmortem analysis contributed to our understanding of ways to improve the cell assembly. However, some further design optimization is required to guarantee uniform and strong contact between the electrodes and separator and the wetting of the separator with electrolyte.

\section{AUTHOR CONTRIBUTIONS}

$\mathrm{CV}$ and MR designed the cell for the neutron experiments with the help of DS. MR and LV collected, respectively, the operando and pristine neutron diffraction data with DS and the help of CV and SS. LV and DS carried out the structural analysis and discussed the results. MR conducted the electrochemical characterization and post-mortem analyses with the help of SS and $\mathrm{CV} . \mathrm{MR}, \mathrm{CV}$, and SS discussed the experiments and the results. $\mathrm{MR}, \mathrm{LV}, \mathrm{CV}$, and DS wrote the manuscript, and all authors approved the final manuscript.

\section{FUNDING}

The authors are grateful to the PSI CROSS initiative for financial support.

\section{ACKNOWLEDGMENTS}

The authors thank H. Kaiser for his valuable help in the design of the cell. This work is partly based on experiments performed at the Swiss spallation neutron source, SINQ, Paul Scherrer Institute, Villigen, Switzerland.
Bergstöm, Ö., Andersson, A. M., Edström, K., and Gustafsson, T. (1998). A neutron diffraction cell for studying lithium-insertion processes in electrode materials. J. Appl. Crystallogr. 31, 823-825. doi: 10.1107/S0021889898 00538X

Bianchini, M., Fauth, F., Suard, E., Leriche, J. B., Masquelier, C., and Croguennec, L. (2015). Spinel materials for Li-ion batteries: new insights obtained by operando neutron and synchrotron X-ray diffraction. Acta Crystallogr. Sect. B Struct. Sci. Cryst. Eng. Mater. 71, 688-701. doi: 10.1107/S2052520615017199

Bianchini, M., Leriche, J.-B., Laborier, J.-L., Gendrin, L., Suard, E., Croguennec, L., et al. (2013). A new null matrix electrochemical cell for Rietveld refinements of in-situ or operando neutron powder diffraction data. J. Electrochem. Soc. 160, A2176-A2183. doi: 10.1149/2.076311jes 
Boulet-Roblin, L., Borel, P., Sheptyakov, D., Tessier, C., Novák, P., and Villevieille, C. (2016). Operando neutron powder diffraction using cylindrical cell design: the case of $\mathrm{LiNi}_{0.5} \mathrm{Mn}_{1.5} \mathrm{O}_{4}$ vs. graphite. J. Phys. Chem. C 120, 17268-17273. doi: 10.1021/acs.jpcc.6b05777

Boulet-Roblin, L., Sheptyakov, D., Borel, P., Tessier, C., Novák, P., and Villevieille, C. (2017). Crystal structure evolution via operando neutron diffraction during long-term cycling of a customized $5 \mathrm{~V}$ full Li-ion cylindrical cell $\mathrm{LiNi}_{0.5} \mathrm{Mn}_{1.5}$ $\mathrm{O}_{4}$ vs. graphite. J. Mater. Chem. A 5, 25574-25582. doi: 10.1039/C7TA07917F

Brant, W. R., Roberts, M., Gustafsson, T., Biendicho, J. J., Hull, S., Ehrenberg, H., et al. (2016). A large format in operando wound cell for analysing the structural dynamics of lithium insertion materials. J. Power Sour. 336, 279-285. doi: 10.1016/j.jpowsour.2016.10.071

Brant, W. R., Schmid, S., Du, G., Brand, H. E. A., Pang, W. K., Peterson, V. K., et al. (2014). In situ neutron powder diffraction using custom-made Lithium-ion batteries. J. Vis. Exp. 10:e52284. doi: 10.3791/52284

Choi, J. W., and Aurbach, D. (2016). Promise and reality of post-lithiumion batteries with high energy densities. Nat. Rev. Mater. 1:16013. doi: $10.1038 /$ natrevmats.2016.13

Choi, W., and Manthiram, A. (2006). Comparison of Metal Ion Dissolutions from Lithium Ion Battery Cathodes. J. Electrochem. Soc. 153:A1760. doi: $10.1149 / 1.2219710$

Colin, J. F., Godbole, V., and Novák, P. (2010). In situ neutron diffraction study of Li insertion in Li4Ti5O12. Electrochem. Commun. 12, 804-807. doi: 10.1016/j.elecom.2010.03.038

Croguennec, L., and Palacin, M. R. (2015). Recent Achievements on inorganic electrode materials for Lithium-ion batteries. J. Am. Chem. Soc. 137, 3140-3156. doi: $10.1021 /$ ja $507828 \mathrm{x}$

Dolotko, O., Senyshyn, A., Mühlbauer, M. J., Nikolowski, K., and Ehrenberg, H. (2014). Understanding structural changes in NMC Liion cells by in situ neutron diffraction. J. Power Sour. 255, 197-203. doi: 10.1016/j.jpowsour.2014.01.010

Dolotko, O., Senyshyn, A., Mühlbauer, M. J., Nikolowski, K., Scheiba, F., and Ehrenberg, H. (2012). Fatigue process in Li-ion Cells: an in situ combined neutron diffraction and electrochemical study. J. Electrochem. Soc. 159, A2082-A2088. doi: 10.1149/2.080212jes

Du, G., Sharma, N., Peterson, V. K., Kimpton, J. A., Jia, D., and Guo, Z. (2011). Br-Doped Li4Ti5O12 and composite $\mathrm{TiO} 2$ anodes for Li-ion batteries: synchrotron X-ray and in situ Neutron Diffraction Studies. Adv. Funct. Mater. 21, 3990-3997. doi: 10.1002/adfm.201100846

Edström, K., Gustafsson, T., and Thomas, J. O. (2004). The cathodeelectrolyte interface in the Li-ion battery. Electrochim. Acta 50, 397-403. doi: 10.1016/j.electacta.2004.03.049

Fischer, P., Frey, G., Koch, M., Könnecke, M., Pomjakushin, V., Schefer, J., et al. (2000). High-resolution powder diffractometer HRPT for thermal neutrons at SINQ. Phys. B Condens. Matter 276, 146-147. doi: 10.1016/S0921-4526(99)01399-X

Ghanty, C., Markovsky, B., Erickson, E. M., Talianker, M., Haik, O., Tal-Yossef, Y., et al. (2015). $\mathrm{Li}^{+}$-Ion extraction/insertion of Ni-Rich $\mathrm{Li}_{1+x}\left(\mathrm{Ni}_{y} \mathrm{Co}_{z}\right.$ $\left.\mathrm{Mn}_{z}\right)_{w} \mathrm{O}_{2}(0.005<x<0.03 ; y: z=8: 1, w \approx 1)$ electrodes: in situ, $\mathrm{X}$. R. D., and Raman Spectroscopy study. ChemElectroChem 2, 1479-1486. doi: $10.1002 /$ celc. 201500160

Godbole, V. A., Heß, M., Villevieille, C., Kaiser, H., Colin, J.-F., and Novák, P. (2013). Circular in situ neutron powder diffraction cell for study of reaction mechanism in electrode materials for Li-ion batteries. RSC Adv. 3, 757-763. doi: $10.1039 / \mathrm{C} 2 \mathrm{RA} 21526 \mathrm{H}$

Ishidzu, K., Oka, Y., and Nakamura, T. (2016). Lattice volume change during charge/discharge reaction and cycle performance of $\mathrm{Li}[\mathrm{Ni}$ x Co y Mn z]O 2. Solid State Ion 288, 176-179. doi: 10.1016/j.ssi.2016.01.009

Kim, N. Y., Yim, T., Song, J. H., Yu, J. S., and Lee, Z. (2016). Microstructural study on degradation mechanism of layered LiNi 0.6 Co $0.2 \mathrm{Mn} 0.2 \mathrm{O} 2$ cathode materials by analytical transmission electron microscopy. J. Power Sour. 307, 641-648. doi: 10.1016/j.jpowsour.2016.01.023

Kondrakov, A. O., Geßwein, H., Galdina, K., de Biasi, L., Meded, V., Filatova, E. O., et al. (2017a). Charge-transfer-induced lattice collapse in Ni-rich NCM cathode materials during delithiation. J. Phys. Chem. C 121, 24381-24388. doi: 10.1021/acs.jpcc.7b06598

Kondrakov, A. O., Schmidt, A., Xu, J., Geßwein, H., Mönig, R., Hartmann, P., et al. (2017b). Anisotropic lattice strain and mechanical degradation of high- and low-nickel NCM cathode materials for li-ion batteries. J. Phys. Chem. C 121, 3286-3294. doi: 10.1021/acs.jpcc.6b12885

Lee, K. S., Myung, S. T., Amine, K., Yashiro, H., and Sun, Y. K. (2007). Structural and electrochemical properties of layered $\mathrm{Li}\left[\mathrm{Ni}_{1-2 x} \mathrm{Co}_{x} \mathrm{Mn}_{x}\right] \mathrm{O}_{2}(\mathrm{x}=0.1-0.3)$ positive electrode materials for Li-ion batteries. J. Electrochem. Soc. 154, A971A977, doi: 10.1149/1.2769831

Li, W., Reimers, J., and Dahn, J. (1993). In situ x-ray diffraction and electrochemical studies of Li1-xNiO2. Solid State Ion 67, 123-130. doi: 10.1016/0167-2738(93)90317-V

Liu, H., Fell, C. R., An, K., Cai, L., and Meng, Y. S. (2013). In-situ neutron diffraction study of the xLi2MnO3.(1 - x)LiMO2 $(x=0,0.5 ; \mathrm{M}=\mathrm{Ni}, \mathrm{Mn}$, Co) layered oxide compounds during electrochemical cycling. J. Power Sour. 240, 772-778. doi: 10.1016/j.jpowsour.2013.04.149

Liu, W., Oh, P., Liu, X., Lee, M. J., Cho, W., Chae, S., et al. (2015). Nickel-rich layered lithium transition-metal oxide for high-energy lithium-ion batteries. Angew. Chem. Int. Ed. 54, 4440-4457. doi: 10.1002/anie.201409262

Manthiram, A., Song, B., and Li, W. (2017). A perspective on nickel-rich layered oxide cathodes for lithium-ion batteries. Energy Storage Mater. 6, 125-139. doi: 10.1016/j.ensm.2016.10.007

Noh, H. J., Youn, S., Yoon, C. S., and Sun, Y. K. (2013). Comparison of the structural and electrochemical properties of layered $\mathrm{Li}[\mathrm{NixCoyMnz}] \mathrm{O} 2$ $(\mathrm{x}=1 / 3,0.5,0.6,0.7,0.8$ and 0.85$)$ cathode material for lithium-ion batteries. J. Power Sour. 233, 121-130. doi: 10.1016/j.jpowsour.2013.01.063

Ohzuku, T., and Ueda, A. (1994). Solid-state redox reactions of licoo2 (R $\overline{3} \mathrm{~m})$ for 4 volt secondary lithium cells. J. Electrochem. Soc. 141, 2972-2977. doi: $10.1149 / 1.2059267$

Pang, W. K., Alam, M., Peterson, V. K., and Sharma, N. (2015). Structural evolution of electrodes in the NCR and CGR cathode-containing commercial lithium-ion batteries cycled between 3.0 and $4.5 \mathrm{~V}$ : an operando neutron powder-diffraction study. J. Mater. Res. 30, 373-380. doi: 10.1557/jmr.2014.297

Pang, W. K., Kalluri, S., Peterson, V. K., Dou, S. X., and Guo, Z. (2014a), Electrochemistry and structure of the cobalt-free $\mathrm{Li}_{1+\mathrm{x}} \mathrm{MO}_{2}(\mathrm{M}=\mathrm{Li}$ Ni, Mn, Fe) composite cathode. Phys. Chem. Chem. Phys. 16, 25377-25385. doi: $10.1039 / \mathrm{C} 4 \mathrm{CP} 02864 \mathrm{C}$

Pang, W. K., and Peterson, V. K. (2015). A custom battery for operando neutron powder diffraction studies of electrode structure. J. Appl. Crystallogr. 48, 280-290. doi: 10.1107/S1600576715000679

Pang, W. K., Peterson, V. K., Sharma, N., Shiu, J.-J., and Wu, S. (2014b). Lithium migration in $\mathrm{Li}_{4} \mathrm{Ti}_{5} \mathrm{O}_{12}$ studied using in situ neutron powder diffraction. Chem. Mater. 26, 2318-2326. doi: 10.1021/cm5002779

Pang, W. K., Sharma, N., Peterson, V. K., Shiu, J.-J., and Wu, S. (2014c). In-situ neutron diffraction study of the simultaneous structural evolution of a LiNi0.5Mn1.5O4 cathode and a Li4Ti5O12 anode in a LiNi0.5Mn1.5O4||Li4Ti5O12 full cell. J. Power Sour. 246, 464-472. doi: 10.1016/j.jpowsour.2013.07.114

Peterson, V. K., Auckett, J. E., and Pang, W. K. (2017). Real-time powder diffraction studies of energy materials under non-equilibrium conditions. IUCrJ 4, 540-554. doi: 10.1107/S2052252517010363

Robert, R., Villevieille, C., and Novák, P. (2014). Enhancement of the high potential specific charge in layered electrode materials for lithium-ion batteries. J. Mater Chem. A 2:8589. doi: 10.1039/c3ta12643a

Roberts, M., Biendicho, J. J., Hull, S., Beran, P., Gustafsson, T., Svensson, G., et al. (2013). Design of a new lithium ion battery test cell for in-situ neutron diffraction measurements. J. Power Sour. 226, 249-255. doi: 10.1016/j.jpowsour.2012.10.085

Rodríguez-Carvajal, J. (1993). Recent advances in magnetic structure determination by neutron powder diffraction. Phys. B Condens. Matter 192, 55-69. doi: 10.1016/0921-4526(93)90108-I

Rodriguez, M. A., Van Benthem, M. H., Ingersoll, D., Vogel, S. C., and Reiche, H. M. (2010). In situ analysis of LiFePO4 batteries: signal extraction by multivariate analysis. Powder Diffr. 25, 143-148. doi: 10.1154/1.3393786

Rosciano, F., Holzapfel, M., Scheifele, W., and Novák, P. (2008). A novel electrochemical cell for in situ neutron diffraction studies of electrode materials for lithium-ion batteries. J. Appl. Crystallogr. 41, 690-694. doi: $10.1107 /$ S0021889808018025

Rozier, P., and Tarascon, J. M. (2015). Review-Li-rich layered oxide cathodes for next-generation Li-ion batteries: chances and challenges. J. Electrochem. Soc. 162, A2490-A2499. doi: 10.1149/2.0111514jes 
Schipper, F., Erickson, E. M., Erk, C., Shin, J. Y., Chesneau, F. F., and Aurbach, D. (2017). Recent advances and remaining challenges for lithium ion battery cathodes I. Nickel-Rich, LiNixCoyMnzO2. J. Electrochem. Soc. 164, A6220-A6228. doi: 10.1149/2.0351701jes

Sears, V. F. (1992). Neutron scattering lengths and cross sections. Neutron News 3, 26-37. doi: 10.1080/10448639208218770

Senyshyn, A., Mühlbauer, M. J., Dolotko, O., Hofmann, M., Pirling, T., and Ehrenberg, H. (2014). Spatially resolved in operando neutron scattering studies on Li-ion batteries. J. Power Sour. 245, 678-683. doi: 10.1016/j.jpowsour.2013.06.158

Shannon, R. D. (1976). Revised effective ionic radii and systematic studies of interatomic distances in halides and chalcogenides. Acta Crystallogr. Sect. A 32, 751-767. doi: 10.1107/S0567739476001551

Sharabi, R., Markevich, E., Borgel, V., Salitra, G., Gershinsky, G., Aurbach, D., et al. (2012). Raman study of structural stability of LiCoPO4 cathodes in LiPF6 containing electrolytes. J. Power Sour. 203, 109-114. doi: 10.1016/j.jpowsour.2011.12.018

Sharma, N., Du, G., Studer, A. J., Guo, Z., and Peterson, V. K. (2011). In-situ neutron diffraction study of the MoS2 anode using a custom-built Li-ion battery. Solid State Ion 199-200, 37-43. doi: 10.1016/j.ssi.2011.07.015

Sharma, N., Guo, X., Du, G., Guo, Z., Wang, J., Wang, Z., et al. (2012). Direct evidence of concurrent solid-solution and two-phase reactions and the nonequilibrium structural evolution of LiFePO 4 . J. Am. Chem. Soc. 134, 7867-7873. doi: 10.1021/ja301187u

Sharma, N., Pang, W. K., Guo, Z., and Peterson, V. K. (2015). In situ powder diffraction studies of electrode materials in rechargeable batteries. ChemSusChem 8, 2826-2853. doi: 10.1002/cssc.201500152

Sharma, N., Peterson, V. K., Elcombe, M. M., Avdeev, M., Studer, A. J., Blagojevic, N., et al. (2010). Structural changes in a commercial lithium-ion battery during electrochemical cycling: an in situ neutron diffraction study. J. Power Sour. 195, 8258-8266. doi: 10.1016/j.jpowsour.2010.06.114

Sharma, N., Yu, D. H., Zhu, Y., Wu, Y., and Peterson, V. K. (2017). In operando neutron diffraction study of the temperature and current rate-dependent phase evolution of LiFePO 4 in a commercial battery. J. Power Sour. 342, 562-569. doi: 10.1016/j.jpowsour.2016.12.048

Sharma, N., Yu, D., Zhu, Y., Wu, Y., and Peterson, V. K. (2013). Non-equilibrium structural evolution of the lithium-rich $\mathrm{Li}_{1+} \mathrm{Mn}_{2} \mathrm{O}_{4}$ cathode within a battery. Chem. Mater. 25, 754-760. doi: 10.1021/cm303851w

Taminato, S., Yonemura, M., Shiotani, S., Kamiyama, T., Torii, S., Nagao, M., et al. (2016). Real-time observations of lithium battery reactions-operando neutron diffraction analysis during practical operation. Sci. Rep. 6: 28843. doi: $10.1038 /$ srep28843
Tarascon, J. M., and Armand, M. (2010). "Issues and challenges facing rechargeable lithium batteries," in Materials for Sustainable Energy, ed V. Dusastre (London: Nature Publishing Group), 171-179. doi: 10.1142/9789814317665_0024

Van der Ven, A., Aydinol, M. K., Ceder, G., Kresse, G., and Hafner, J. (1998). First-principles investigation of phase stability in Li x CoO 2. Phys. Rev. B 58, 2975-2987. doi: 10.1103/PhysRevB.58.2975

Yabuuchi, N., and Ohzuku, T. (2003). Novel lithium insertion material of LiCo1/3Ni1/3Mn1/3O2 for advanced lithium-ion batteries. J. Power Sour. 119-121, 171-174. doi: 10.1016/S0378-7753(03)00173-3

Yin, S. C., Rho, Y. H., Swainson, I., and Nazar, L. F. (2006). X-ray/neutron diffraction and electrochemical studies of lithium De/Re-intercalation in $\mathrm{Li}_{1-x} \mathrm{Co}_{1 / 3} \mathrm{Ni}_{1 / 3} \mathrm{Mn}_{1 / 3} \mathrm{O}_{2}(x=0 \rightarrow 1)$. Chem. Mater. 18, 1901-1910. doi: $10.1021 / \mathrm{cm} 0511769$

Yoon, W. S., Chung, K. Y., McBreen, J., and Yang, X.-Q. (2006). A comparative study on structural changes of $\mathrm{LiCo}_{1 / 3} \mathrm{Ni}_{1 / 3} \mathrm{Mn}_{1 / 3} \mathrm{O}_{2}$ and $\mathrm{LiNi}_{0.8} \mathrm{Co}_{0.15} \mathrm{Al}_{0.05} \mathrm{O}_{2}$ during first charge using in situ XRD. Electrochem. Commun. 8, 1257-1262. doi: 10.1016/j.elecom.2006.06.005

Yu, H., Qian, Y., Otani, M., Tang, D., Guo, S., Zhu, Y., et al. (2014). Study of the lithium/nickel ions exchange in the layered $\mathrm{LiNi}_{0.42} \mathrm{Mn}_{0.42} \mathrm{Co}_{0.16} \mathrm{O}_{2}$ cathode material for lithium ion batteries: experimental and first-principles calculations. Energy Environ. Sci. 7:1068. doi: 10.1039/C3EE42398K

Zhao, E., Fang, L., Chen, M., Chen, D., Huang, Q., Hu, Z., et al. (2017). $\mathrm{New}$ insight into $\mathrm{Li} / \mathrm{Ni}$ disorder in layered cathode materials for lithium ion batteries: a joint study of neutron diffraction, electrochemical kinetic analysis and first-principles calculations. J. Mater. Chem. A 5, 1679-1686. doi: 10.1039/C6TA08448F

Zheng, H., Sun, Q., Liu, G., Song, X., and Battaglia, V. S. (2012). Correlation between dissolution behavior and electrochemical cycling performance for $\mathrm{LiNi}_{1 / 3} \mathrm{Co}_{1 / 3} \mathrm{Mn}_{1 / 3} \mathrm{O}_{2}$-based cells. J. Power Sour. 207, 134-140. doi: 10.1016/j.jpowsour.2012.01.122

Conflict of Interest Statement: The authors declare that the research was conducted in the absence of any commercial or financial relationships that could be construed as a potential conflict of interest.

Copyright (c) 2018 Vitoux, Reichardt, Sallard, Novák, Sheptyakov and Villevieille. This is an open-access article distributed under the terms of the Creative Commons Attribution License (CC BY). The use, distribution or reproduction in other forums is permitted, provided the original author(s) and the copyright owner(s) are credited and that the original publication in this journal is cited, in accordance with accepted academic practice. No use, distribution or reproduction is permitted which does not comply with these terms. 